\title{
SEISMIC PERFORMANCE OF BUILDINGS WITH THIN RC BEARING WALLS
}

\author{
H. Gonzales ${ }^{a}$, F. López-Almansa ${ }^{b^{*}}$ \\ ${ }^{a}$ Technical University of Catalonia, Geotechnical Engineering and Geosciences Department, Jordi Girona 18, 08034 Barcelona, Spain \\ ${ }^{b}$ Technical University of Catalonia, Architecture Structures Department, Avda. Diagonal 649, 08028 Barcelona, Spain
}

\begin{abstract}
In Latin America there is an urgent need for housing; thus, during the last few years a relevant number of mid-height buildings (usually, up to five stories) with thin RC shear-walls have been constructed for low-cost dwellings in Bolivia, Colombia, Ecuador, Mexico, Peru, Venezuela, and other countries located in seismic-prone regions. These walls are $10 \mathrm{~cm}$ thick and their reinforcement consists mainly of a single layer of welded wire mesh. This construction technology offers two main advantages: economy and rapidity of construction. These buildings do not fulfill the international seismic codes but some national regulations are less demanding, not preventing the use of thin bearing walls. These buildings might be vulnerable to earthquakes because of their low ductility, the insufficiency of the experimental information, the absence of observed damages and, in some cases, poor construction quality. This work describes the initial steps of a wider research aiming at providing reliable seismic design guidelines for thin-wall buildings; the initial objectives are analyzing the seismic performance of these buildings, proposing preliminary design criteria and identifying further research needs. This research focuses on buildings located in Peru, being representative of the situations in the other countries. The vulnerability is numerically evaluated by push-over and nonlinear time history analyses; the structural parameters are obtained from available testing information. The obtained results show that the seismic strength of the analyzed buildings is insufficient; however, minor changes in the structural design might improve significantly their seismic performance. Economical and easy-to-implement design recommendations are issued.
\end{abstract}

KEY WORDS: seismic vulnerability, thin supporting walls, reinforced concrete, push-over analysis, nonlinear time history analysis.

\section{Introduction}

Due to several reasons, in most of the cities of Latin America there is an urgent need for housing. Conversely, the involved countries do not have the capacity of constructing the required number of buildings, provided they have to be designed and built to fulfill the usual standards for developed countries. Given this situation, during the last few years a relevant number of mid-height buildings (usually, up to five stories) with thin shear-walls made of reinforced concrete have been constructed for low-cost dwellings in Colombia [1], Mexico [2], Peru [3], Venezuela [4], and other developing countries located in seismic-prone regions of Latin America. These walls are the only vertical carrying-load members; normally they are $10 \mathrm{~cm}$ thick and their reinforcement consists basically of a single layer of cold-rolled welded wire mesh. This construction technology offers two main advantages: economy (because of little consumption of materials and of work force) and rapidity of construction. Nowadays, many thin shear-wall buildings are under construction in Peru and other close countries.

These buildings do not fulfill the major international seismic design codes, as [5] and [6], among others. Conversely some national codes [7-9] are less demanding, thus do not prevent the use of $10 \mathrm{~cm}$ thick bearing walls; e.g. the Mexican Metropolitan code [10] allows the use of $10 \mathrm{~cm}$ thick supporting walls for up to two stories. Concerns about the seismic performance of these buildings might arise; beyond the high stiffness, thus leading to high base-shear coefficients, main sources of seismic vulnerability are: apparent low ductility, scarcity of experimental information, no past experience of behavior under strong earthquakes, use of low-strength concrete, and, in some cases, poor construction quality. Accordingly, Muñoz et al. [3] have shown that these buildings might be vulnerable.

This work belongs to a wider research project aiming to provide seismic design guidelines for thin-wall buildings. That project consists of the following non-consecutive stages:

- Numerical seismic evaluation of a number of existing thin-wall buildings.

* Corresponding author. Tel.: +34 93 4016316,+34 606807733; fax: +34 934016096. E-mail address: francesc.lopez-almansa@upc.edu (F. López-Almansa). 
- Full-scale testing of individual walls and of wall-slab assemblies.

- Formulation of design guidelines.

- Parametrical numerical study of the seismic efficiency of buildings that fulfill these requirements.

- Proposal of retrofit strategies.

This work describes the first stage of the research project. The objectives of this paper are: analyzing the seismic performance of a number of existing buildings, proposing preliminary design criteria and identifying further research needs, useful for the next stages. This work focuses on buildings located in Peru, being representative of the situations in the other countries.

The first step of the research described in this paper consists of selecting seven representative thin-wall buildings. Then, their vulnerability is assessed by numerical simulation using the PERFORMD-3D program [11,12]; both static nonlinear (push-over) and nonlinear time-history analyses are carried out. For the dynamic analyses, the inputs are selected to represent the highest seismicity in Peru, mainly in the Pacific coastal regions; both impulsive and vibratory accelerograms are considered. Given the high stiffness of the buildings, the soil-structure interaction has been considered; the behavior of the soil has been described by nonlinear vertical springs. The results of the push-over and dynamic analyses allow assessing the vulnerability of the considered buildings and formulating preliminary design guidelines. As well, some remaining research needs are identified.

\section{Considered buildings}

\subsection{Thin-wall buildings in Peru}

Over 2500 thin-wall buildings have been constructed in Peru for low-cost housing, mainly after 2001 [13]. This subsection contains a description of such buildings and a selection of seven representative ones.

As discussed previously, the main reinforcement of the walls consists merely of a single layer of cold-rolled welded wire mesh; however, in the most recent buildings, in the lowest floors such mesh is made with hot-rolled bars. The boundary elements at the ends of the walls consist simply of additional reinforcement bars, without any confinement effect. Given the rather reduced size of the rooms, the wall density is usually over 3\% in each direction, and the span-lengths are short, averaging $3.5 \mathrm{~m}$ and generally do not exceed $6 \mathrm{~m}$; hence, the floor slabs are normally $12 \mathrm{~cm}$ thick RC plates. The clear height ranges usually between $2.40 \mathrm{~m}$ and $2.65 \mathrm{~m}$. Commonly, there are no basements and the foundation consists of a concrete mat whose depth ranges between 20 and $25 \mathrm{~cm}$. Fig. 1(a) displays a picture of a typical building and Fig. 1(b) shows a plan view of one of their floors. Fig. 1(a) shows that there are coupling beams among neighboring walls. However, such beams do not fulfill the requirements stated regularly in the design codes (e.g. thickness and reinforcement details).

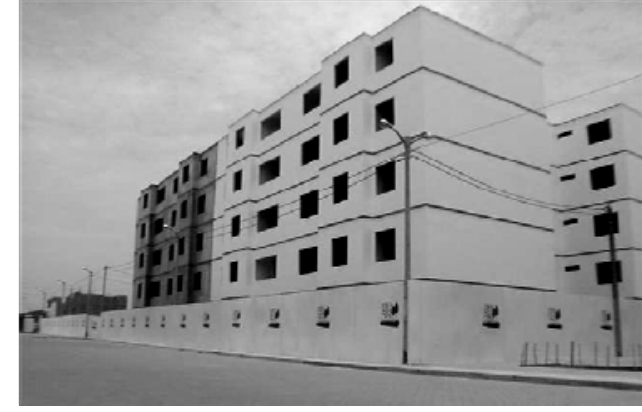

(a) Image of a building

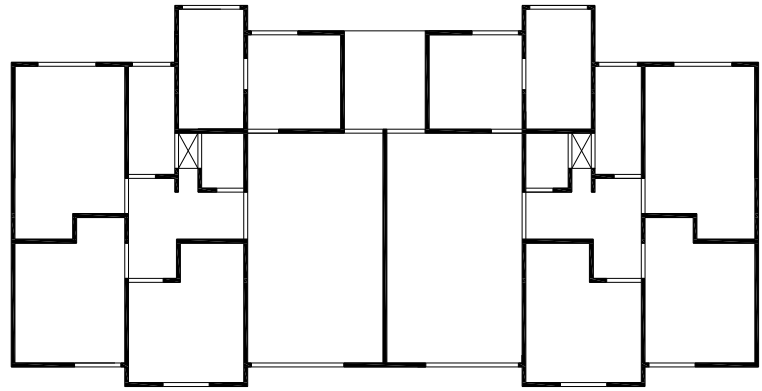

(b) Plan floor

Fig. 1. Building with thin walls

Seven existing buildings have been selected to represent the vast majority of the actual buildings with thin walls in Peru. The main characteristics of these buildings are described in Table 1. Buildings C1 and C2 are located in 
Chiclayo (northern Peru) and buildings L1 to L5 are located in Lima; both cities belong to the zone with highest seismicity in Peru. The soil has been classified according to the Peruvian seismic design code [8]. The wall density in each direction is defined as the ratio between the areas of the walls (in such direction) and the plan area; the connected walls are split in individual ones assigned to their corresponding directions. The directions with the maximum and minimum wall densities are referred as X (strong) and $\mathrm{Y}$ (weak), respectively. In the connected walls, their moments of inertia have been calculated accounting for the contribution of the flanges; the effective widths have been determined according to [14]. Ninth column contains the ratios between the moments of inertia of the walls and those of the plan area. Fig. 1 corresponds to building C2. The last two columns contain the plan regularity and the response reduction factor assumed by the designers.

Table 1. Main characteristics of the representative buildings

\begin{tabular}{|c|c|c|c|c|c|c|c|c|c|c|}
\hline Bldng. & $\begin{array}{c}\text { Stories / } \\
\text { height } \\
(\mathbf{m})\end{array}$ & $\begin{array}{l}\text { Soil } \\
\text { type }\end{array}$ & Year & $\begin{array}{c}\text { Plan area } \\
\left(\mathrm{m}^{2}\right)\end{array}$ & $\begin{array}{l}\text { Wall areas } \\
\qquad\left(\mathbf{m}^{2}\right)\end{array}$ & $\begin{array}{c}\text { Wall } \\
\text { densities } \\
(\%) \\
\end{array}$ & $\begin{array}{c}\text { Wall } \\
\text { moments of } \\
\text { inertia }\left(\mathrm{m}^{4}\right) \\
\end{array}$ & $\begin{array}{c}\text { Ratio of } \\
\text { moments of } \\
\text { inertia (\%) }\end{array}$ & $\begin{array}{c}\text { Assumed } \\
\text { plan } \\
\text { config. }\end{array}$ & $\begin{array}{c}\text { Red. } \\
\text { factor } \\
(R)\end{array}$ \\
\hline $\mathrm{C} 1$ & $5 / 13.10$ & Soft & 2005 & $14.5 \times 14.9$ & $5.91 / 4.34$ & $3.82 / 2.42$ & $21.71 / 4.04$ & $9.02 / 1.98$ & Irregular & 3 \\
\hline $\mathrm{C} 2$ & $5 / 13.75$ & Soft & 2004 & $9.70 \times 19.4$ & $6.80 / 3.20$ & $4.24 / 2.38$ & $22.57 / 1.59$ & $4.55 / 1.56$ & Regular & 4 \\
\hline L1 & $5 / 12.75$ & Int. & 2002 & $21.8 \times 19.8$ & $10.51 / 9.18$ & $3.25 / 2.75$ & $43.16 / 14.85$ & $3.81 / 1.33$ & Regular & 6 \\
\hline L2 & $4 / 10.20$ & Stiff & 2004 & $24.6 \times 15.0$ & $12.50 / 6.33$ & $4.36 / 2.11$ & $68.71 / 10.97$ & $12.07 / 0.93$ & Regular & 4 \\
\hline L3 & $5 / 12.75$ & Stiff & 2004 & $24.9 \times 10.0$ & 11.69 / 3.32 & $5.44 / 1.39$ & 43.25 / 2.99 & $22.91 / 0.34$ & Irregular & 3 \\
\hline L4 & $5 / 12.10$ & Stiff & 2003 & $16.6 \times 12.1$ & $5.95 / 5.88$ & $3.78 / 3.74$ & 8.75 / 12.62 & $4.41 / 3.86$ & Regular & 5 \\
\hline L5 & $5 / 12.10$ & Stiff & 2003 & $15.1 \times 28.0$ & $11.35 / 10.12$ & 3.49 / 3.11 & $24.83 / 12.72$ & $1.25 / 2.95$ & Regular & 5 \\
\hline
\end{tabular}

Buildings in Table 1 do not have any basement, have plan symmetry (e.g. the mass and stiffness centers are near coincident) and are fully uniform along their height. In spite that there are some actual buildings that do not exhibit these characteristics, have not been considered in this study since they represent only a small percentage.

\subsection{Code-type seismic design of the considered buildings}

The buildings listed in Table 1 were designed according to the Peruvian seismic code [8]; it is based on UBC [15] and provides mainly criteria to determine the base-shear coefficient. That regulation was first issued in 2003, without any specific provision regarding thin shear-wall buildings. A relevant amendment dealing with these types of buildings was published in 2004 [16]; noticeably, in that document they are referred as "limited ductility wall buildings" (EMDL). The amendment consisted basically of defining the values of the response reduction coefficient $R: R=4$ and $R=3$ were chosen for regular and irregular buildings, respectively (see the last two columns of Table 1); the previous code [8] stated $R=6$ (for shear-wall buildings). Other recommendations are similar to the usual requirements [14] for shear-wall buildings; two issues are particularly relevant for short to mid-height buildings similar to those listed in Table 1: (i) the lateral behavior of thin shear-wall buildings could be described with equivalent frame models accounting for the flange stiffening effect of the intersecting orthogonal walls, and (ii) the maximum allowed inter-story drift is 0.005 . The EMDL code states that the confinement boundary elements in the wall ends are required only if the well known inequality linking the neutral axis position and the horizontal displacement of the top floor [14,17] is not fulfilled; according to this criterion, in most of the cases such confinement is not needed. In spite of the construction years indicated in Table 1, these buildings fulfill only some of the requirements of EMDL code.

\subsection{Numerical modeling of the structural behavior}

The structural behavior of the considered thin-wall buildings is described by finite-element models whose parameters are obtained mainly from experiments carried out in Peru [18-20]. The tested specimens were both full-scale individual walls and full-scale single-storey wall assemblies; the experiments consisted basically of imposing cyclic horizontal displacement laws to these specimens until failure. The effect of the upper floors was represented by constant vertical forces.

The static and dynamic nonlinear structural behaviors of the representative buildings (Table 1) are described by a 
$1^{\text {st }}$ order, three-dimensional finite-element model implemented in the PERFORM-3D program [11,12]. Fig. 2 depicts such a model for building L1.

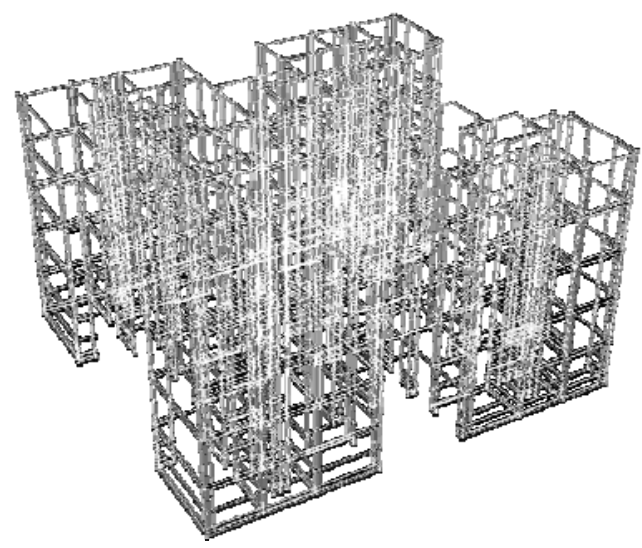

Fig. 2. Finite-element model of building L1

Two types of instabilities might arise in the structural behavior of the considered buildings: global buckling of the building and local buckling of the thin walls. About the first type, the global second order effects are not considered because the ratios between the actual vertical loads and their critical values are small [21,22]. About the second type of instability, undoubtedly the risk of local buckling of the walls might be serious, given their slenderness; remarkably, for clear height equal to $2.40 \mathrm{~m}$ most of the seismic design codes [5,6,23-25] prevent the use of thickness smaller than about $12 \mathrm{~cm}$. However, the structural analyses carried out inside this study have shown that, except for the impulsive records (see subsection 4.1), the vertical stresses in the concrete of the walls are sufficiently lower than the allowable value (see Fig. 3(b)); consequently, it is unfeasible that any local instability could amplify it until reaching such level. Moreover, the plan layout of the considered buildings (see Fig. 1) shows that most of the unflanged wall ends correspond to inner parts of the buildings, where the expectable cyclic increases of vertical stresses are smaller.

As shown in Fig. 2, the walls are discretized by quadrangular 4-node shell elements. The in-plane nonlinear behavior of the walls is described by a plastic hinge located in their base: the vertical length of each hinge is selected as suggested in [26]; in most of the cases, such height is equal to half of the horizontal length of the wall. The out-of-plane bending is assumed to be linear. The coupling beams are described by 3-D 2-node frame elements. The contribution of the slabs to such beams is represented by an effective width determined according to [14]. No other contribution of the slabs to the lateral strength of the building is considered; however, their diaphragm effect is included. In building $\mathrm{C} 1$ (Table 1), a more detailed model discretizing the slabs with plate elements was also generated; the results of the analyses were similar for both cases. For the modal and dynamic analyses the masses are concentrated, following a lumped-masses approach, in the centroid of every floor; the rotational inertia has been also considered.

The flexural behavior of the walls is described by a fiber model as shown in Fig. 3(a); the behavior of concrete is represented by the stress-strain constitutive law shown in Fig. 3(b). This law is taken from [27] by neglecting the tensile strength; this model has been chosen since it describes accurately the structural behavior of unconfined concrete [28]. The characteristic value $f^{\prime}$ c of the concrete compressive strength is estimated from field rebound hammer tests carried out by one of the authors; the deformation modulus $E_{\mathrm{c}}$ is determined from $f^{\prime}$ ' according to [14]. The behavior of the reinforcement steel is described by an uniaxial tri-linear law [29]; their modulus of elasticity, their yielding point, and their ultimate stress and strain are taken from tests described in [30]. Noticeably, the parameters for the cold-rolled and the hot-rolled steels are different. 


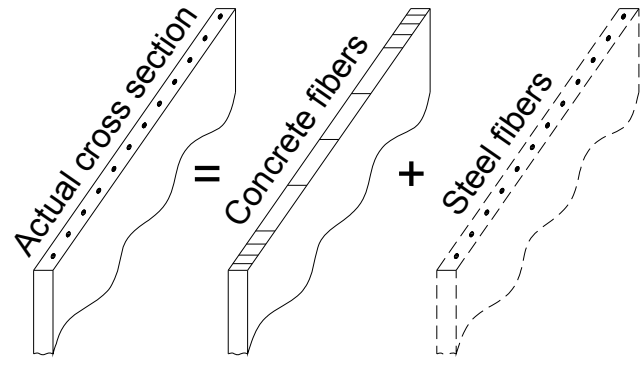

(a) Fiber model

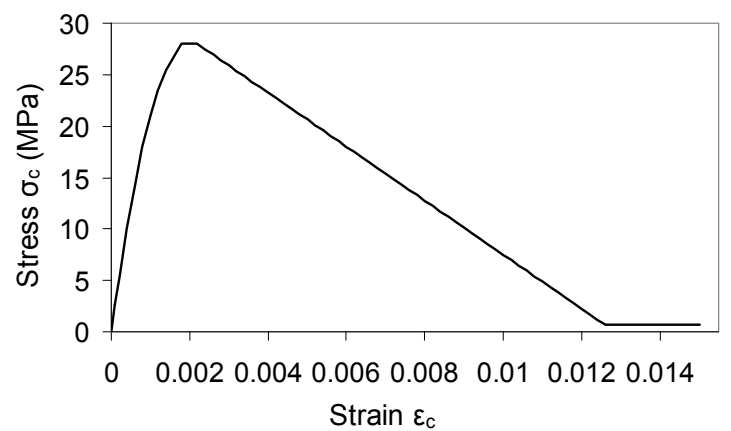

(b) Uniaxial constitutive law of concrete

Fig. 3. Flexural model of the thin walls

The shear behavior of the walls is described by a composite steel-concrete model; Fig. 4(b) shows its tri-linear constitutive law [31]. For shear strains not higher than about 0.005 , this law is the envelope (back-bone curve) of the experimental stress-strain curves (Fig. 4(a)) obtained in [20] from uniaxial cyclic testing of a single-storey full-scale housing model and seven single squat walls (height-length ratio $<1.5$ ); for shear strains higher than about 0.005 , the stiffness and strength degradations are accounted for by decreasing branches. Fig. 4(a) displays the curves considered in [32-34] together with the curve proposed in this study, which is also plotted in Fig. 4(b). The proposed curve is derived according the recommendations in [33].

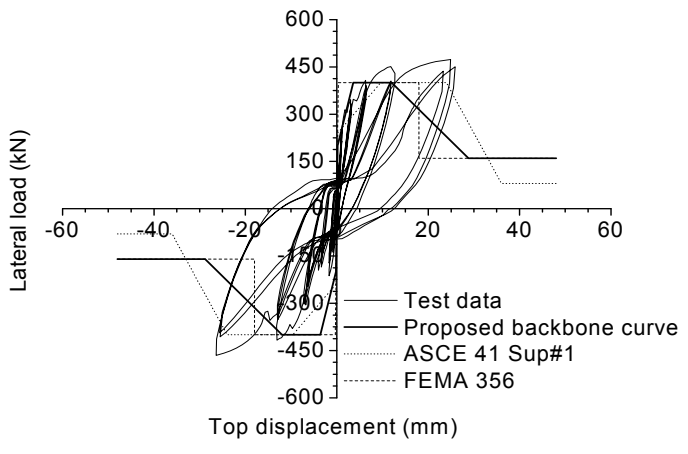

(a) Experimental loops [20]

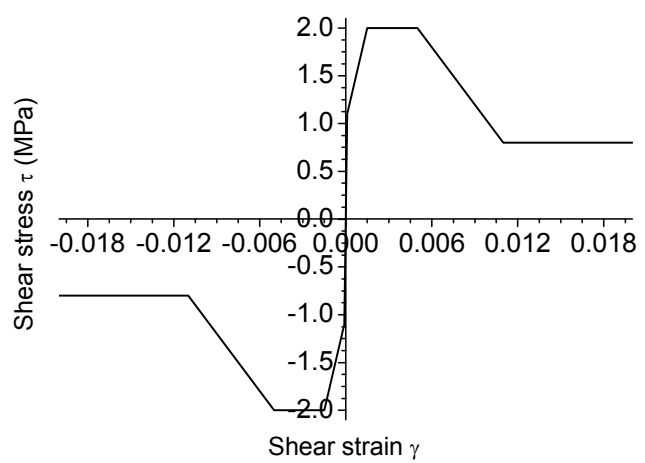

(b) Back-bone envelope

Fig. 4. Shear model of the thin walls

The hysteretic behavior of the coupling beams is described by rigid-plastic shear hinges [35] located in their mid span. The transversal (horizontal) bending and the torsion are assumed to be linear.

The stiffness and strength degradation are further accounted for by specifying energy degradation factors for concrete and steel [36]. These factors are the ratios between the areas of the degraded and non-degraded hysteresis loops, respectively.

The accuracy of this model is checked by comparison with quasi-static in-plane shear cyclic tests of individual squat walls [19]. Fig. 5 presents comparisons between numerical and experimental hysteresis loops [19]. 


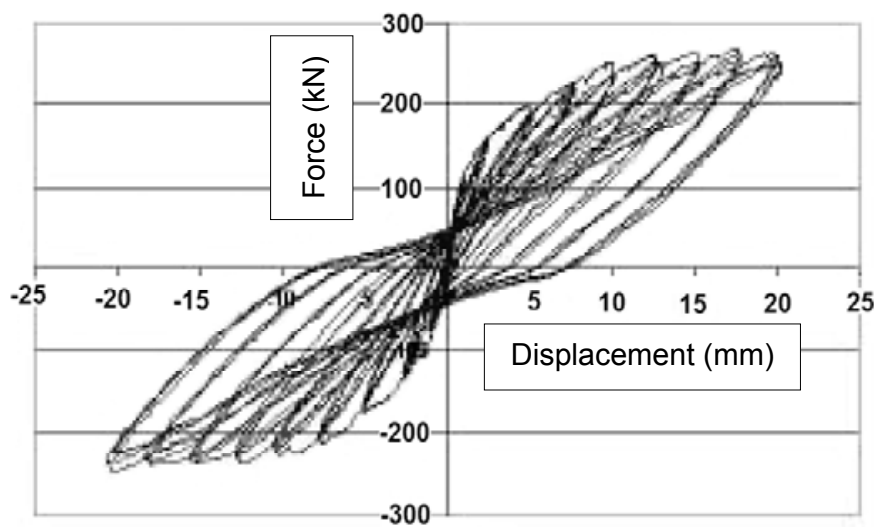

(a) Observed response [19]

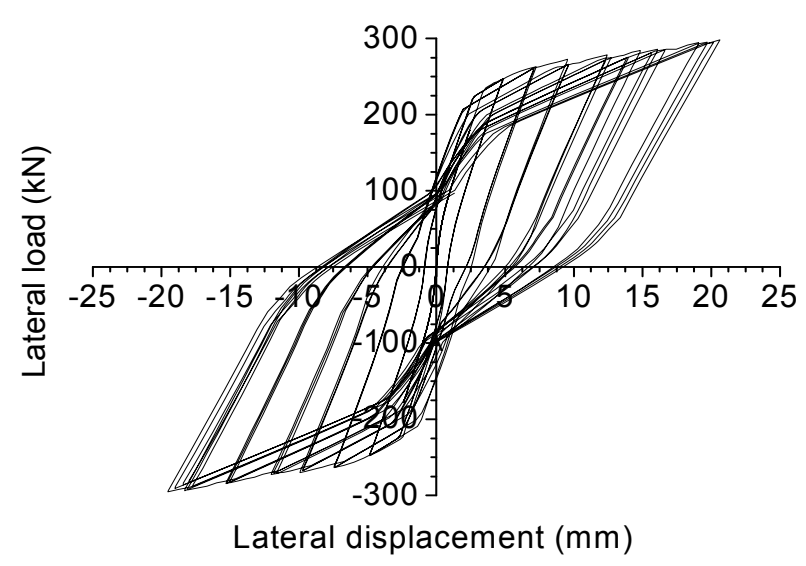

(b) Calculated response

Fig. 5. Comparison of experimental and numerical responses

\subsection{Measurements on the representative buildings}

No empirical expressions for the fundamental period of thin-wall buildings have been proposed in the technical literature; if simplified expressions derived for regular shear-wall buildings $[5,6,8,23]$ are used instead, high scattering is obtained. Therefore, ambient vibration measurements were conducted on buildings L4 and L5 to estimate its fundamental period; other proofs carried out on similar buildings in Lima provided close results. Table 2 displays the obtained results, together with the results determined according to the European and Peruvian regulations and with values provided by modal analyses using the PERFORM-3D program [11,12]; SSI accounts for soil-structure interaction. Two different expressions from the EC-8 [6] have been used; expression (1) accounts only for the height of the building while expression (2) considers also other parameters such as the wall density and their vertical slenderness (related to the moment of inertia of the wall, without accounting for the contribution of the flanges). For the other considered regulations [5,23], the results are similar.

Table 2. Fundamental periods (s) of the representative buildings

\begin{tabular}{|c|c|c|c|c|c|c|c|c|c|c|c|c|}
\hline \multirow[b]{2}{*}{ Bldng. } & \multicolumn{6}{|c|}{ Direction X } & \multicolumn{6}{|c|}{ Direction Y } \\
\hline & Exp. & $\begin{array}{c}\text { EC-8 } \\
\text { (1) }\end{array}$ & $\begin{array}{c}\text { EC-8 } \\
\text { (2) }\end{array}$ & E.030 & $\begin{array}{c}\text { Num. } \\
\text { (w/o } \\
\text { SSI) }\end{array}$ & $\begin{array}{c}\text { Num. } \\
\text { (w } \\
\text { SSI) }\end{array}$ & Exp. & $\begin{array}{c}\text { EC-8 } \\
\text { (1) }\end{array}$ & $\begin{array}{c}\text { EC-8 } \\
\text { (2) }\end{array}$ & E.030 & $\begin{array}{c}\text { Num. } \\
\text { (w/o } \\
\text { SSI) }\end{array}$ & $\begin{array}{c}\text { Num. } \\
\text { (w } \\
\text { SSI) }\end{array}$ \\
\hline $\mathrm{C} 1$ & - & 03 & 0.39 & 0.22 & 0.08 & 0.19 & - & 0.34 & 0.71 & 0.22 & 0.12 & 0.20 \\
\hline $\mathrm{C} 2$ & - & & 0.39 & & 0.11 & 0 . & - & 0. & 1.03 & 3 & 0.17 & 0.24 \\
\hline L1 & - & 0.34 & 0.38 & 0.21 & 0.11 & 0.14 & - & 0.34 & 0.69 & 0.21 & 0.15 & 0.17 \\
\hline L2 & - & 0.29 & 0.14 & 0.17 & 0.07 & 0.10 & - & 0.29 & 0.41 & 0.17 & 0.14 & 0.16 \\
\hline L3 & - & 0.34 & 0.38 & 0.21 & 0.07 & 0.10 & - & 034 & 0.69 & 0.21 & 0.23 & 0.25 \\
\hline L4 & 0.14 & & 0.50 & & 0.11 & & 0.12 & 0.52 & 0.42 & 0.20 & 0.10 & 0.16 \\
\hline L5 & 0.12 & 0.32 & 0.31 & 0.20 & 0.11 & 0.13 & 0.13 & 0.32 & 0.37 & 0.20 & 0.12 & 0.14 \\
\hline
\end{tabular}

Results from Table 2 allow deriving the following general conclusions: (i) the design codes overestimate the natural periods, (ii) the EC-8 [6] provides significantly higher periods than the E.030 [8], (iii) in the weak direction, the expression (2) of EC-8 [6] provides extremely long periods, and (iv) the agreement between the experimental results and those provided by numerical simulation (accounting for the soil-structure) interaction is satisfactory.

\section{Push-over analyses}

\subsection{Push-over analyses of the representative buildings}

The seismic performance of the representative buildings (Table 1) has been assessed by 2D nonlinear static analyses (push-over) by using the PERFORM-3D program [11,12]; the model described in subsection 2.3 has 
been considered to describe its structural behavior. In the push-over analyses two patterns have been considered for the lateral forces: triangular and first modal shape; since the contribution of the higher modes is small, they have not been accounted for [37]. The analyses are stopped when any of the set of predetermined ultimate states of the walls is reached; in this study three bounds are stated: concrete vertical compressive strain $\left(\varepsilon_{\mathrm{c}}=0.015\right.$, see Fig. $3(b))$, axial strain of the vertical steel reinforcement $\left(\varepsilon_{\mathrm{s}}=0.2\right.$ for conventional bars and $\varepsilon_{\mathrm{s}}=0.065$ for wire mesh), and global shear strain $(\gamma=0.02$, see Fig. 4(b)). Such bounds are suggested in $[29,30]$. No limit has been established for the coupling beams since their failure is earlier than the shear failure on the walls.

Figs. 6 to 12 show the capacity curves of the selected buildings C1, C2, L1, L2, L3, L4 and L5, respectively; in those Figs., the soil-structure interaction is not considered. The lateral forces pattern is triangular; similar results are obtained for the other considered pattern. For comparison purposes, the drift limit equal to $0.5 \%$ [16] is also plotted. Three Damage Limit States (DLS) corresponding to different Performance Objectives (or Levels) [33] are considered: "Immediate Occupancy" (IO), "Life Safety" (LS) and "Collapse Prevention" (CP); for each of them, three thresholds are established: flexural and shear behavior of the walls and shear behavior of the coupling beams. The flexural thresholds of the walls are defined in terms of the rotations in the plastic hinges [26]; the bounds are $0.002 \mathrm{rad}$ (IO), $0.004 \mathrm{rad}(\mathrm{LS})$ and $0.008 \mathrm{rad}$ (CP). Such values are established as recommended in [33]. The overall Damage Limit States of each building have been conservatively defined as the most critical of those of the members that the structure is composed of. The shear thresholds of the walls are defined in terms of the shear strains; the bounds are 0.0025 (IO), 0.00375 (LS) and 0.005 (CP), see Fig. 4(b). Such values are established based on experiments carried out on squat thin walls whose reinforcements are similar to those in the considered buildings [20]. The thresholds of the coupling beams are defined in terms of the chord rotation [32]; the bounds are 0.005 (IO), 0.01 (LS) and 0.02 (CP). Such values are established based on [32]. In the coupling beams the failure of the diagonal struts might be relevant, given that the web is thin and the concrete strength is low; this failure mode has been verified according to European regulations [38]. The "Coefficient Method" is used to determine the Target Drift (TD) points; it is assumed that $C_{2}=1$ [32]. The buildings in Table 1 are considered as basic facilities; therefore, IO corresponds to the Occasional Input (return period 72 years), LS corresponds to the Rare Input (return period 475 years) and CP corresponds to the Very Rare Input (return period 975 years) [39].

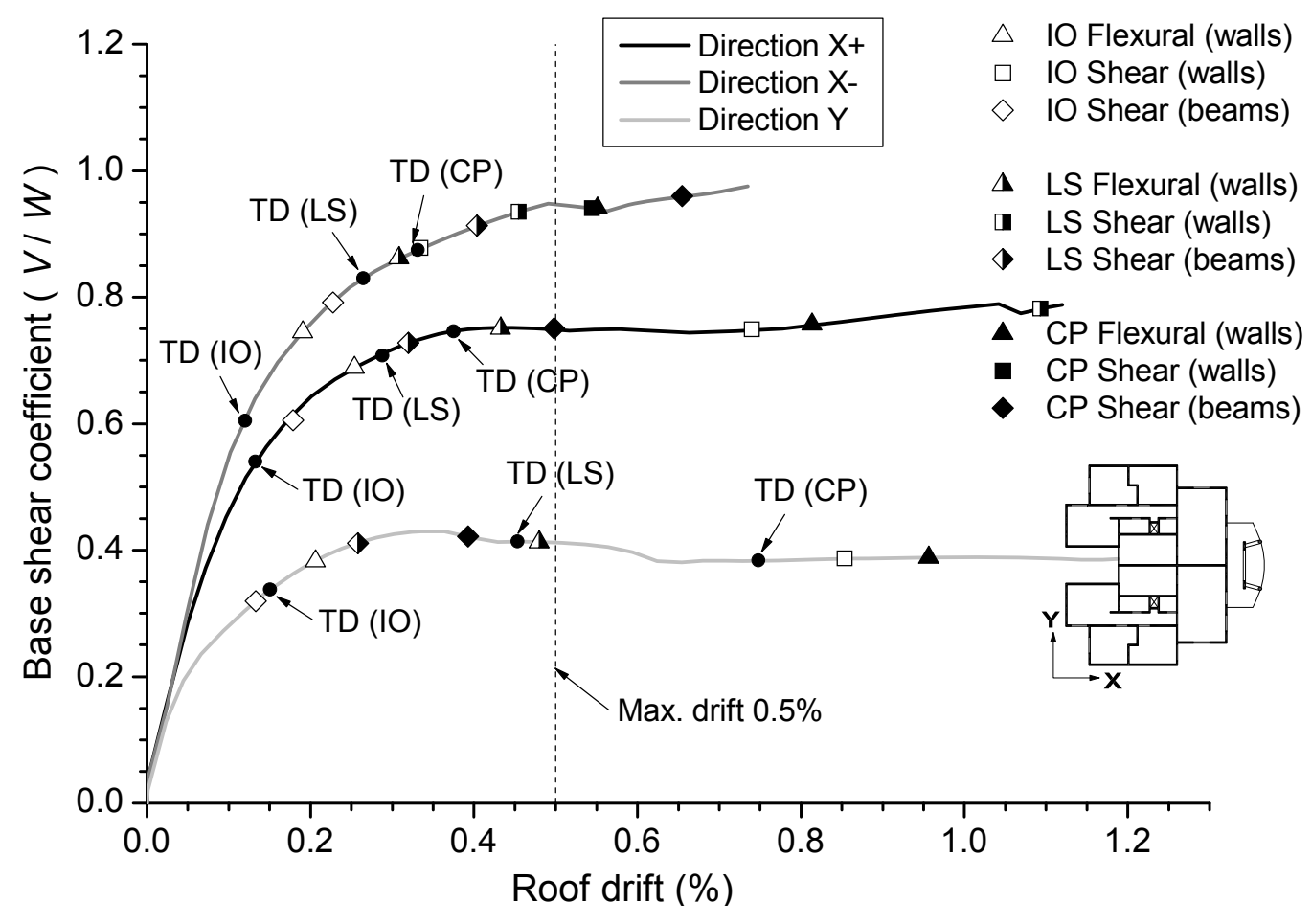

Fig. 6. Capacity curves of building $\mathrm{C} 1$ 


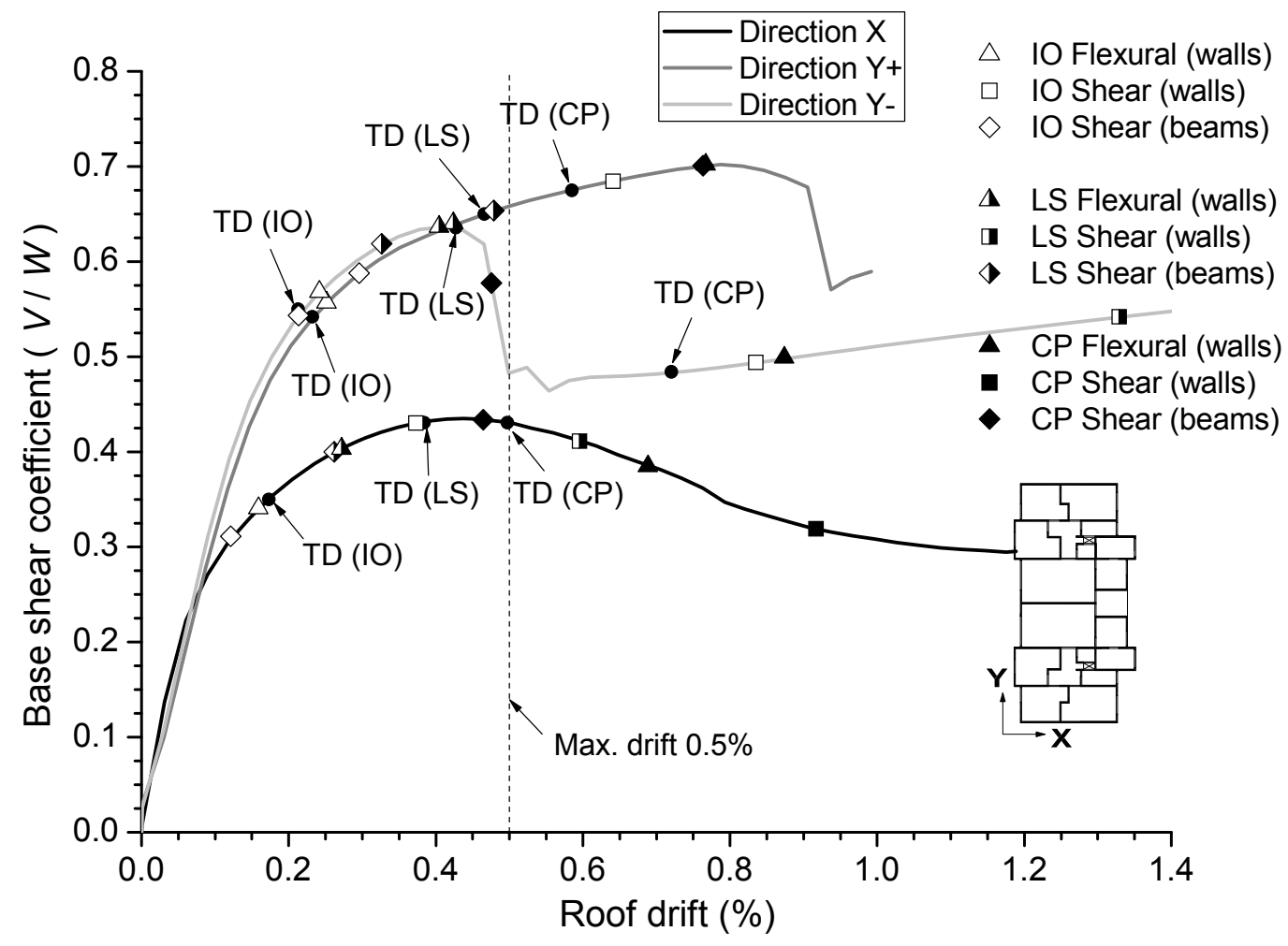

Fig. 7. Capacity curves of building C2

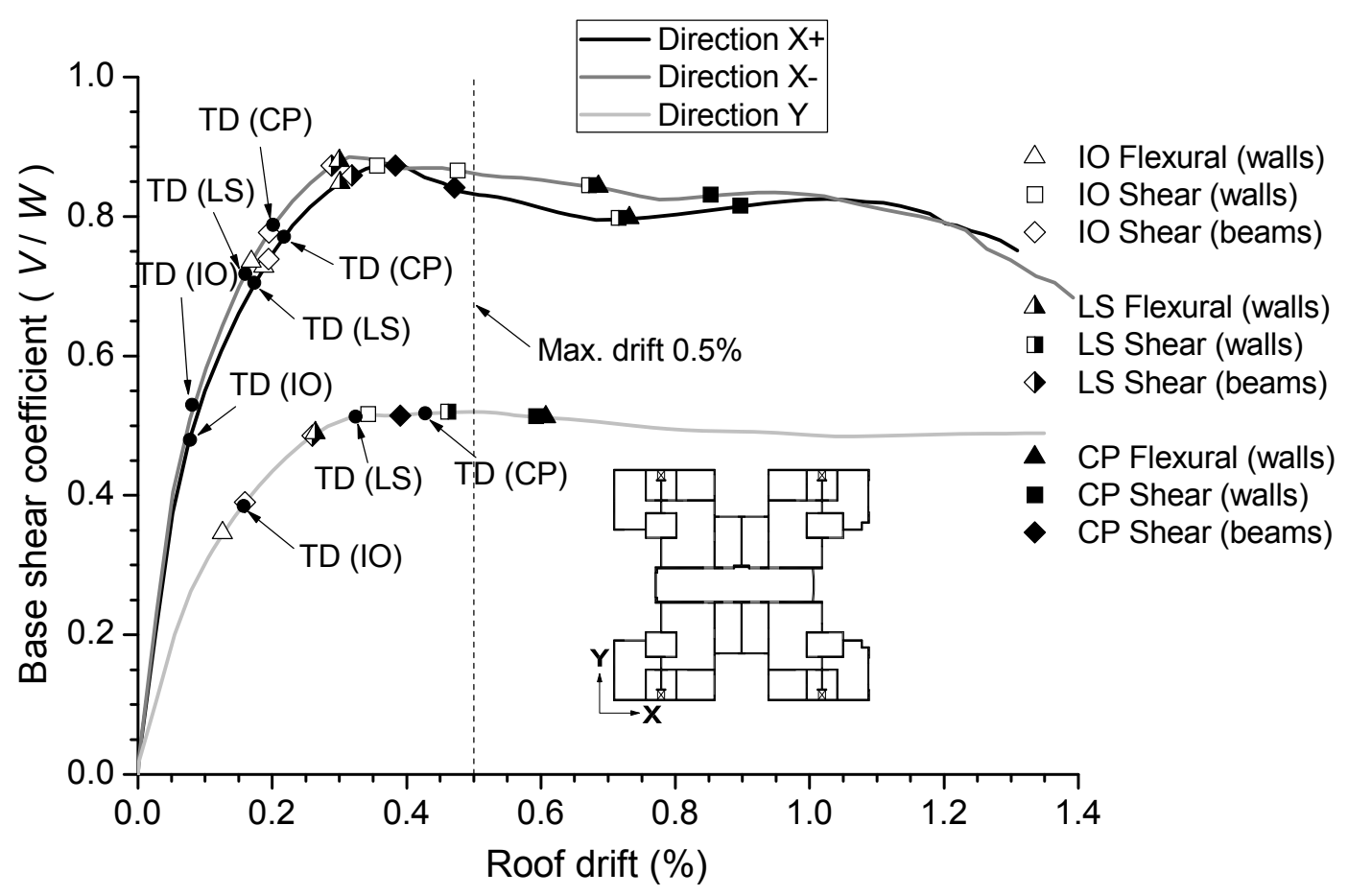

Fig. 8. Capacity curves of building L1 


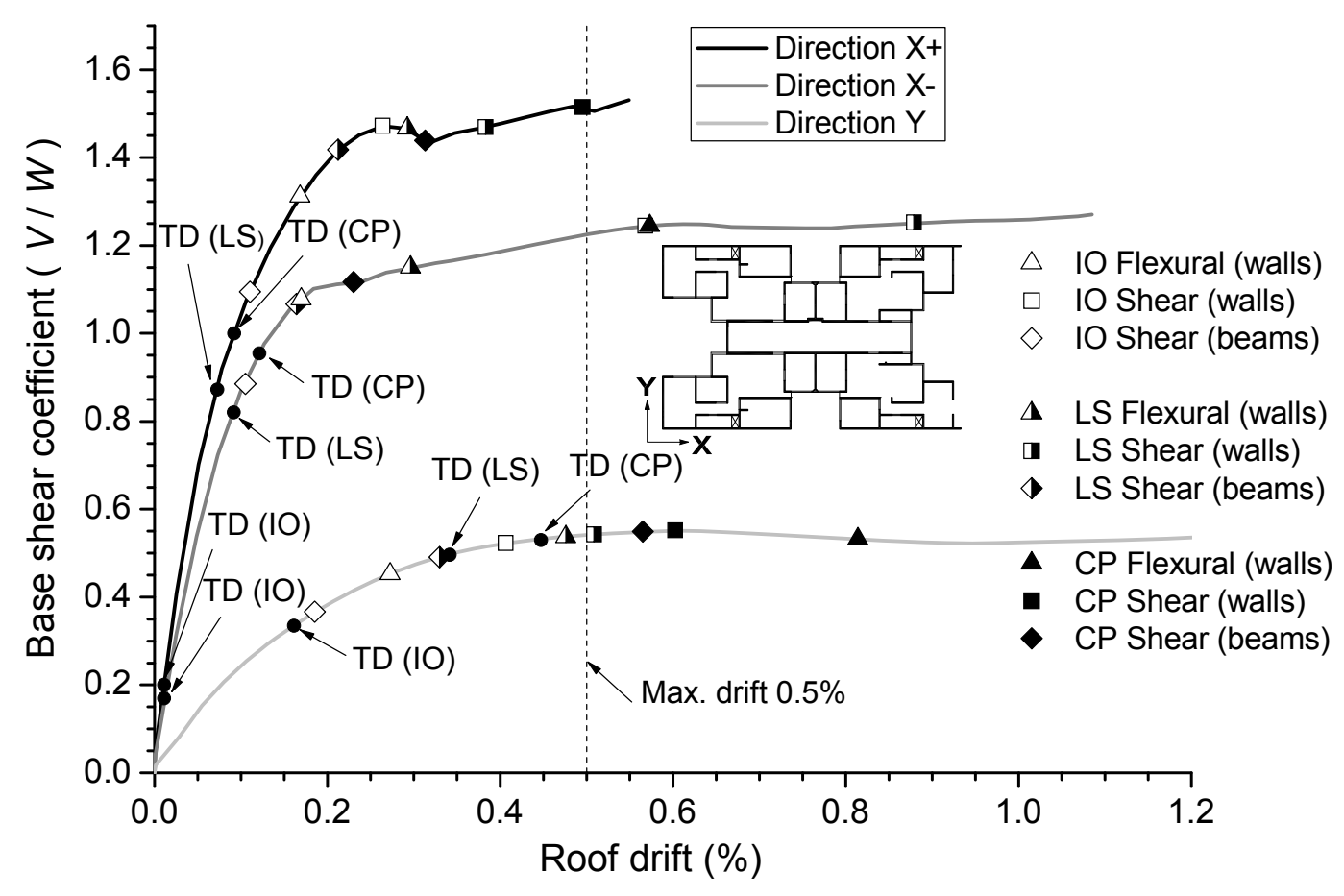

Fig. 9. Capacity curves of building L2

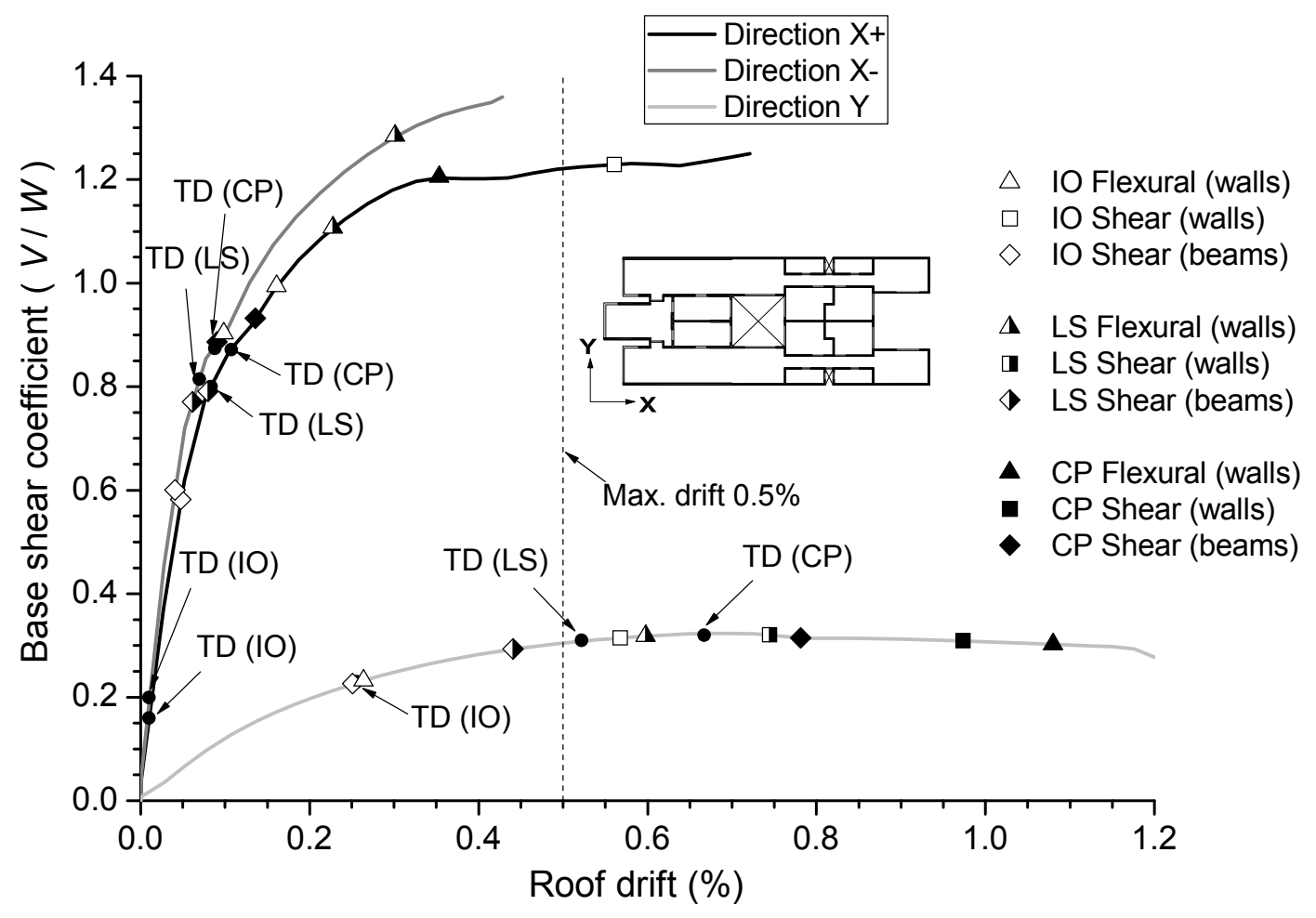

Fig. 10. Capacity curves of building L3 


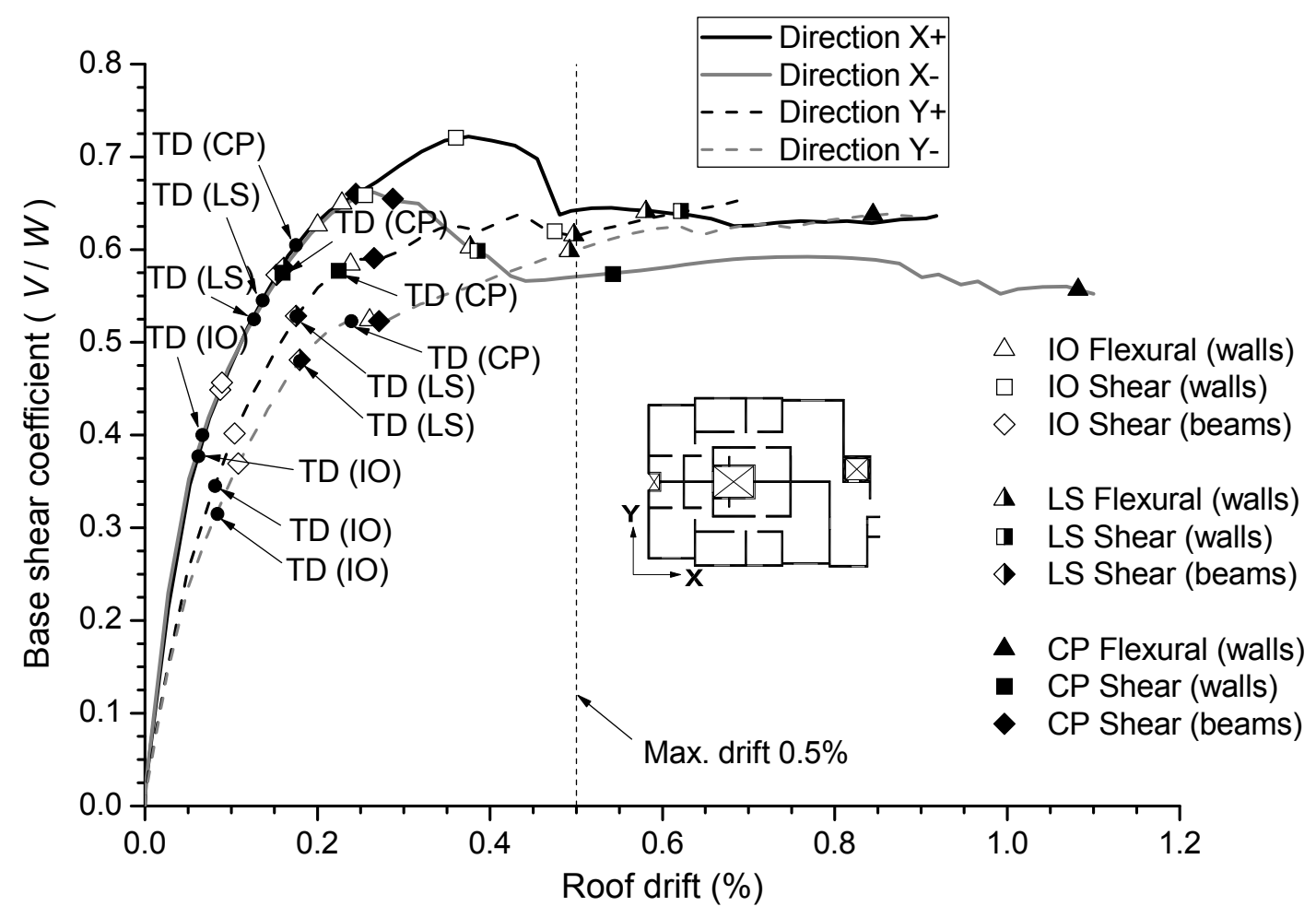

Fig. 11. Capacity curves of building L4

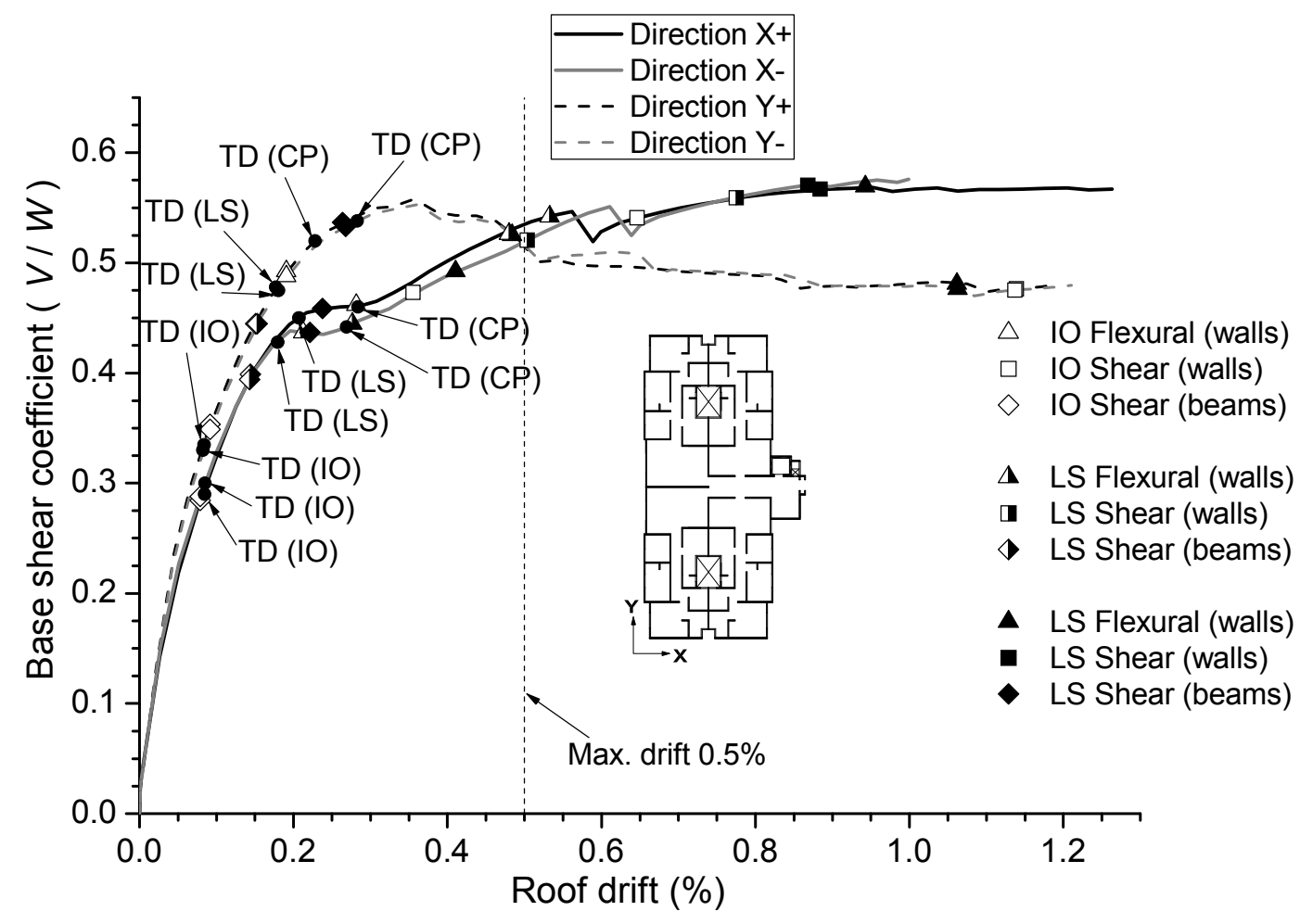

Fig. 12. Capacity curves of building L5

Table 3 displays, for the seven representative buildings, the Target Drifts (TD) and the most critical Damage Limit States (DLS) for "Immediate Occupancy" (IO), "Life Safety" (LS) and "Collapse Prevention" (CP). The type of Damage Limit State is indicated as "beams" (shear failure of the coupling beams) or "walls" (flexural failure in 
the base of the walls). The cases in which the Target Drifts are larger than the corresponding limit states, this fact meaning that the behavior is not adequate, have been highlighted with italics.

Table 3. Main results of the push-over analyses of the representative buildings

\begin{tabular}{|c|c|c|c|c|c|}
\hline Building & $\begin{array}{c}\text { Performance } \\
\text { objective }\end{array}$ & $\begin{array}{c}\text { Direction X+ } \\
\text { TD / DLS (\%) }\end{array}$ & $\begin{array}{c}\text { Direction X- } \\
\text { TD / DLS (\%) }\end{array}$ & $\begin{array}{c}\text { Direction Y+ } \\
\text { TD / DLS (\%) }\end{array}$ & $\begin{array}{c}\text { Direction Y- } \\
\text { TD / DLS (\%) }\end{array}$ \\
\hline \multirow{3}{*}{$\mathrm{C} 1$} & $\mathrm{IO}$ & $0.133 / 0.179$ (beams) & $0.120 / 0.191$ (walls) & 0.150 / 0.133 (beams) & 0.150 / 0.133 (beams) \\
\hline & LS & $0.288 / 0.319$ (beams) & $0.264 / 0.308$ (walls) & 0.453 / 0.258 (beams) & $0.453 / 0.258$ (beams) \\
\hline & $\mathrm{CP}$ & 0.375 / 0.498 (beams) & $0.331 / 0.544$ (walls) & 0.748 / 0.393 (beams) & 0.748 / 0.393 (beams) \\
\hline \multirow{3}{*}{$\mathrm{C} 2$} & $\mathrm{IO}$ & $0.232 / 0.251$ (walls) & $0.213 / 0.213$ (beams) & $0.173 / 0.121$ (beams) & 0.173 / 0.121 (beams) \\
\hline & LS & $0.466 / 0.424$ (walls) & $0.427 / 0.327$ (beams) & 0.384 / 0.262 (beams) & 0.384 / 0.262 (beams) \\
\hline & $\mathrm{CP}$ & $0.585 / 0.763$ (beams) & $0.720 / 0.476$ (beams) & 0.497 / 0.464 (beams) & 0.497 / 0.464 (beams) \\
\hline \multirow{3}{*}{ L1 } & $\mathrm{IO}$ & $0.081 / 0.188$ (walls) & $0.078 / 0.169$ (walls) & $0.158 / 0.126$ (walls) & $0.158 / 0.126$ (walls) \\
\hline & LS & 0.173 / 0.301 (walls) & $0.160 / 0.288$ (beams) & 0.324 / 0.260 (beams) & 0.324 / 0.260 (beams) \\
\hline & $\mathrm{CP}$ & $0.217 / 0.471$ (beams) & $0.201 / 0.383$ (beams) & $0.428 / 0.391$ (beams) & 0.428 / 0.391 (beams) \\
\hline \multirow{3}{*}{ L2 } & $\mathrm{IO}$ & $0.011 / 0.111$ (beams) & $0.011 / 0.105$ (beams) & $0.161 / 0.186$ (beams) & $0.161 / 0.186$ (beams) \\
\hline & LS & $0.072 / 0.212$ (beams) & $0.092 / 0.164$ (beams) & 0.342 / 0.330 (beams) & 0.342 / 0.330 (beams) \\
\hline & $\mathrm{CP}$ & $0.092 / 0.313$ (beams) & $0.121 / 0.230$ (beams) & $0.447 / 0.565$ (beams) & $0.447 / 0.565$ (beams) \\
\hline \multirow{3}{*}{ L3 } & $\mathrm{IO}$ & $0.010 / 0.048$ (beams) & $0.010 / 0.041$ (beams) & $0.256 / 0.251$ (beams) & $0.256 / 0.251$ (beams) \\
\hline & LS & $0.083 / 0.080$ (beams) & $0.069 / 0.061$ (beams) & 0.522 / 0.441 (beams) & 0.522 / 0.441 (beams) \\
\hline & $\mathrm{CP}$ & $0.107 /$ & $0.088 /$ & $0.667 /$ & 1 (beams) \\
\hline \multirow{3}{*}{ L4 } & $\mathrm{IO}$ & $0.066 / 0.087$ (beams) & $0.062 / 0.089$ (beams) & $0.081 / 0.104$ (beams) & $0.084 / 0.108$ (beams) \\
\hline & LS & $0.136 / 0.152$ (beams) & $0.127 / 0.161$ (beams) & 0.176 / 0.175 (beams) & 0.180 / 0.179 (beams) \\
\hline & $\mathrm{CP}$ & $0.175 / 0.244$ (beams) & $0.159 / 0.288$ (beams) & $0.225 / 0.266$ (beams) & $0.239 / 0.271$ (beams) \\
\hline \multirow{3}{*}{ L5 } & $\mathrm{IO}$ & 0.085 / 0.079 (beams) & 0.085 / 0.079 (beams) & $0.082 / 0.091$ (beams) & 0.084 / 0.091 (beams) \\
\hline & LS & 0.207 / 0.144 (beams) & 0.180 / 0.143 (beams) & $0.177 / 0.151$ (beams) & $0.181 / 0.153$ (beams) \\
\hline & $\mathrm{CP}$ & $0.284 / 0.238$ (beams) & $0.269 / 0.221$ (beams) & $0.228 / 0.264$ (beams) & $0.233 / 0.268$ (beams) \\
\hline
\end{tabular}

\subsection{Conclusions from the push-over analyses of the representative buildings}

Curves from Figs. 6 to 12 and data from Table 3 show that none of the considered buildings exhibit an adequate behavior for the three performance levels (IO, LS and CP) in both directions; in the strong direction only buildings C1, L1, L2 and L4, behave satisfactorily behavior for levels IO, LS and CP. As well, such results allow deriving the following additional conclusions:

- In spite of the linear appearance of most of the initial branches, a closer view shows that the early onset of cracking in the walls generates actual nonlinear branches. Therefore, the fundamental periods calculated from linear elastic analyses, are significantly lengthened even for small seismic demanding forces.

- Most of the Damage Limit States correspond to shear failure of the coupling beams. In all the cases, the shear failure of the walls occurs after the other types of failure.

- Except in building $\mathrm{C} 2$, the maximum base-shear coefficients for each building correspond to the strong direction. In some cases, such coefficients are remarkably high, reaching more than 1.5 in the $\mathrm{X}+$ direction of building L2.

- In buildings L2 and L3 the initial stiffness in both directions are clearly different. This dissimilarity has been confirmed by the authors carrying out several linear analyses and can be explained by the relevant differences in the plan length and the wall areas and moments of inertia (Table 1).

- The decreasing segments of the capacity curves (buildings C2, L1, L4 and L5) correspond mainly to the descending branches of the rigid-plastic shear hinges of the coupling beams.

Table 4 displays the values of the displacement ductility $\left(\mu_{\Delta}\right)$ and of the response reduction factor $(R)$ for the seven representative buildings (Table 1). The displacement ductility is determined, from the capacity curves shown in Figs. 6 to 12, as the ratio between the most critical failure mode of the walls corresponding to Collapse Prevention (CP) and the yield drift [40]; it is established as the end of the initial linear branch. The response reduction factor $R$ is determined as the product of the force modification factor $R_{\mathrm{d}}$ and the over-strength factor $R_{0} . R_{\mathrm{d}}$ is the ratio between the elastic design force, corresponding to the design spectrum in the Peruvian code [8], and the ultimate 
force given by the capacity curve; $R_{0}$ is the ratio between such ultimate force and the yielding one [41].

Table 4. Displacement ductility $\left(\mu_{\Delta}\right)$ and response reduction factor $\left(R=R_{\mathrm{d}} R_{0}\right)$ for the representative buildings

\begin{tabular}{|c|c|c|c|c|c|c|c|c|c|c|c|c|c|c|c|c|}
\hline \multirow{2}{*}{ Bldng. } & \multicolumn{4}{|c|}{ Direction X+ } & \multicolumn{4}{|c|}{ Direction X- } & \multicolumn{4}{|c|}{ Direction Y+ } & \multicolumn{4}{|c|}{ Direction Y- } \\
\hline & $\mu_{\Delta}$ & $\boldsymbol{R}_{\mathrm{d}}$ & $\boldsymbol{R}_{\mathbf{0}}$ & $\boldsymbol{R}$ & $\mu_{\Delta}$ & $\boldsymbol{R}_{\mathrm{d}}$ & $\boldsymbol{R}_{\mathbf{0}}$ & $\boldsymbol{R}$ & $\mu_{\Delta}$ & $\boldsymbol{R}_{\mathrm{d}}$ & $\boldsymbol{R}_{\mathbf{0}}$ & $\boldsymbol{R}$ & $\mu_{\Delta}$ & $\boldsymbol{R}_{\mathrm{d}}$ & $\boldsymbol{R}_{\mathbf{0}}$ & $\boldsymbol{R}$ \\
\hline $\mathrm{C} 1$ & 6.90 & 1.86 & 1.99 & 3.76 & 6.80 & 1.49 & 1.98 & 2.95 & 11.79 & 3.32 & 2.60 & 8.63 & 11.79 & 3.32 & 2.60 & 8.63 \\
\hline $\mathrm{C} 2$ & 5.09 & 2.00 & 1.65 & 3.30 & 3.40 & 2.43 & 1.28 & 3.11 & 6.63 & 3.23 & 1.93 & 6.23 & 6.63 & 3.23 & 1.93 & 6.23 \\
\hline L1 & 8.66 & 1.43 & 2.10 & 3.00 & 7.04 & 1.37 & 2.18 & 2.99 & 5.74 & 2.33 & 2.17 & 5.06 & 5.74 & 2.33 & 2.17 & 5.06 \\
\hline $\mathrm{L} 2$ & 5.92 & - & 1.98 & - & 4.35 & - & 2.03 & - & 8.90 & 3.14 & 1.82 & 5.71 & 8.90 & 3.14 & 1.82 & 5.71 \\
\hline L3 & 2.85 & 1.07 & 1.60 & 1.71 & 1.90 & 1.13 & 1.52 & 2.15 & 7.81 & 3.17 & 2.52 & 7.99 & 7.81 & 3.17 & 2.52 & 7.99 \\
\hline L4 & 5.16 & 1.51 & 1.96 & 2.96 & 6.07 & 1.53 & 1.94 & 2.97 & 5.04 & 1.69 & 2.15 & 3.63 & 5.16 & 1.91 & 1.90 & 3.63 \\
\hline L5 & 5.91 & 2.18 & 2.45 & 5.34 & 5.50 & 2.29 & 2.33 & 5.34 & 6.75 & 1.86 & 2.51 & 4.67 & 6.86 & 1.88 & 2.49 & 4.68 \\
\hline
\end{tabular}

In the strong direction of building L2, the actual value of factor $R_{\mathrm{d}}$ is not shown because it is smaller than 1 ; it means that the design spectrum in the Peruvian code [8] does not correspond to the actual strength in that direction.

Results in Table 4 allow deriving the following conclusions:

- The displacement ductility factors $\mu_{\Delta}$ show high scattering ranging between 1.90 (building L3, direction X-) and 11.79 (building C1, weak direction). Except in building L1 and L4, the highest factors correspond to the weak direction.

- The force response reduction factors $R$ show high scattering ranging between 1.71 (building L3, direction $\mathrm{X}+$ ) and 8.63 (building $\mathrm{C} 1$, weak direction). Except in building L5, the highest response reduction factors correspond to the weak direction.

- Comparison with the values of factor $R$ in the Peruvian code [16] (see the last column of Table 1) shows that in a significant number of cases such values are not conservative.

In the references $[29,42]$ it is recommended that, to avoid excessive hinging, the tension strain on the boundary vertical steel reinforcement of the walls does not exceed about $1 \%$. Table 5 displays the obtained values of such strains for the Target Drifts corresponding to the three considered performance objectives. Values in Table 5 show that for Immediate Occupancy (IO) only one of the walls exceed the aforementioned limit; for Life Safety (LS) and Collapse Prevention (CP) over half of the cases exceed such limit.

\begin{tabular}{ccccccccc}
\multicolumn{2}{c}{ Table 5. Tension strain (\%) of the boundary vertical steel reinforcement of the walls } \\
$\begin{array}{c}\text { Performance } \\
\text { Level }\end{array}$ & Direction & C1 & C2 & L1 & L2 & L3 & L4 & L5 \\
\hline \multirow{4}{*}{ IO } & X+ & 0.62 & 0.80 & 0.25 & 0.03 & 0.04 & 0.20 & 0.19 \\
& X- & 0.41 & 1.47 & 0.27 & 0.04 & 0.04 & 0.18 & 0.18 \\
& Y+ & 0.55 & 0.59 & 0.45 & 0.46 & 0.63 & 0.20 & 0.20 \\
& Y- & 0.55 & 0.59 & 0.45 & 0.46 & 0.63 & 0.20 & 0.21 \\
& X+ & 1.98 & 2.41 & 1.41 & 0.41 & 0.32 & 0.34 & 0.42 \\
LS & X- & 1.87 & 3.41 & 1.25 & 0.60 & 0.26 & 0.29 & 0.36 \\
& Y+ & 2.08 & 1.90 & 1.93 & 1.68 & 1.75 & 0.51 & 0.39 \\
& Y- & 2.08 & 1.90 & 1.93 & 1.68 & 1.75 & 0.47 & 0.52 \\
& X+ & 2.68 & 3.23 & 1.82 & 0.65 & 0.41 & 0.43 & 0.56 \\
CP & X- & 2.39 & 4.49 & 1.69 & 0.98 & 0.40 & 0.35 & 0.50 \\
& Y+ & 2.83 & 2.44 & 2.86 & 2.47 & 2.27 & 0.72 & 0.48 \\
& Y- & 2.83 & 2.44 & 2.86 & 2.47 & 2.27 & 0.70 & 0.76 \\
\hline
\end{tabular}

\subsection{Push-over analyses with soil-structure interaction}

Since the considered buildings are highly stiff, the soil-structure interaction is considered. The flexural behavior of the foundation mat is described by plate elements. Given the high flexibility of the mat, no extensive cracking is expected; hence, its behavior is assumed to be linear. The soil flexibility is described by vertical spring elements 
connecting the foundation mat and the soil. The behavior of such springs is elastic-plastic without strain hardening [32,43-47]; it is characterized by the initial stiffness, the yield stress and the ultimate strain capacity: the initial stiffness is obtained [32] from the sub-grade modulus, the yield stress is estimated to be 1.5 times the soil bearing capacity [48], and the ultimate strain capacity is defined as 4 times the yield strain. The sub-grade modulus and the soil bearing capacity have been obtained from geotechnical studies. Given the low height of the buildings, the uplift has not been considered. The satisfactory agreement among the measured natural periods and those obtained by numerical simulation accounting for the soil-structure interaction (see Table 2) shows that the accuracy of this model is sufficient. Fig. 13 shows a comparison among the capacity curves for building $\mathrm{C} 1$ obtained considering and neglecting the soil-structure interaction, respectively.

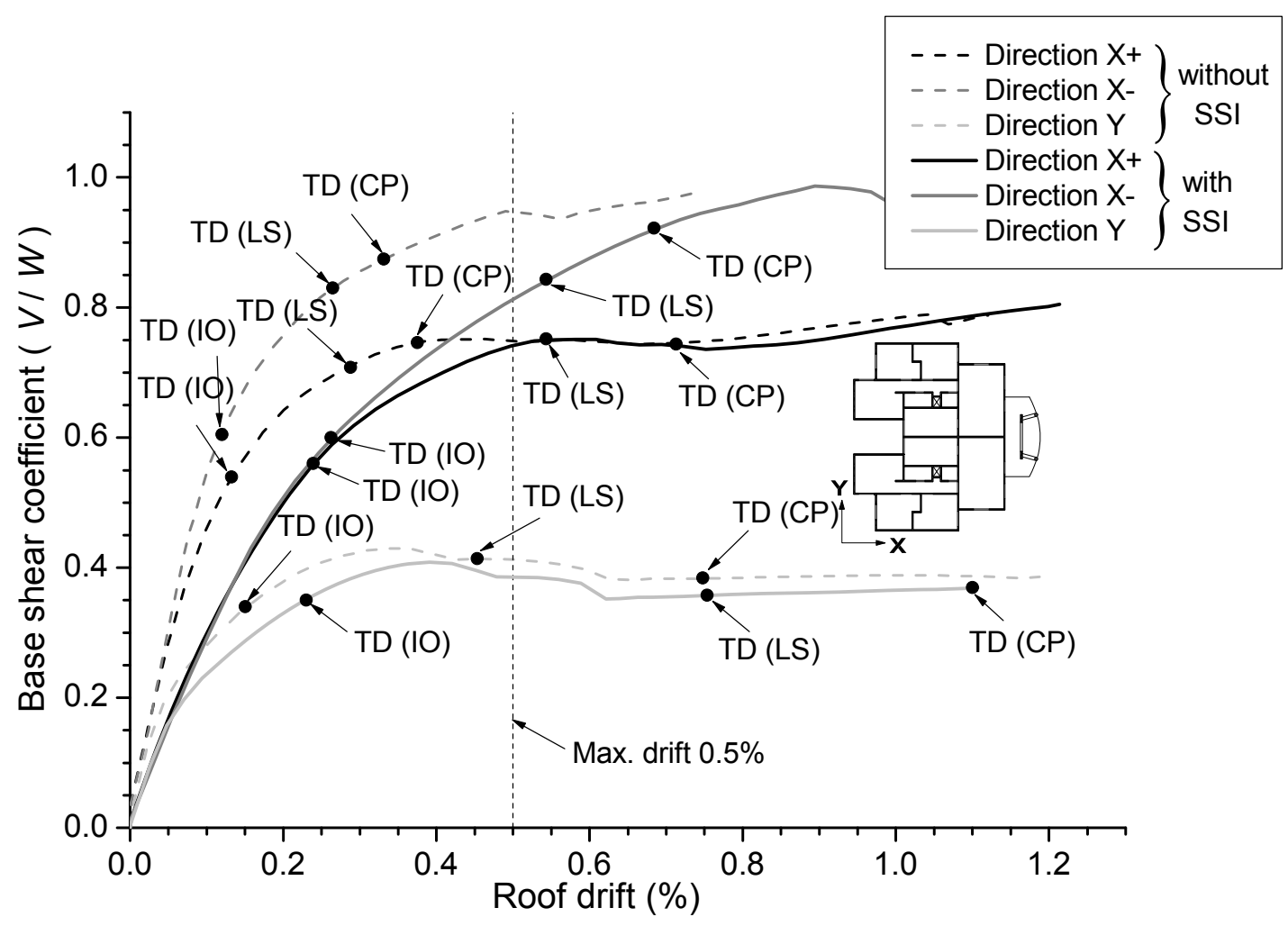

Fig. 13. Influence of the soil-structure interaction in the capacity curves of building $\mathrm{C} 1$

Curves in Fig. 13 show that the soil-structure interaction influences the stiffness and the Target Drifts; this last effect is mainly contributed by the yielding of the soil. Conversely, the effects on the yielding and ultimate forces and on the response reduction factor are less relevant; consequently, it might be preliminary concluded that the design base-shear cannot be significantly reduced by the consideration of the soil-structure interaction.

\subsection{Push-over analyses with strengthened coupling beams}

The results of the push-over analyses described in subsection 3.1 have shown that most of the failure modes initiate by shear failure of the coupling beams. Hence, minor strengthening measures might lead to significant overall benefits; Figs. 14(a) and 14(b) show cross section details of actual and strengthened coupling beams, respectively. 


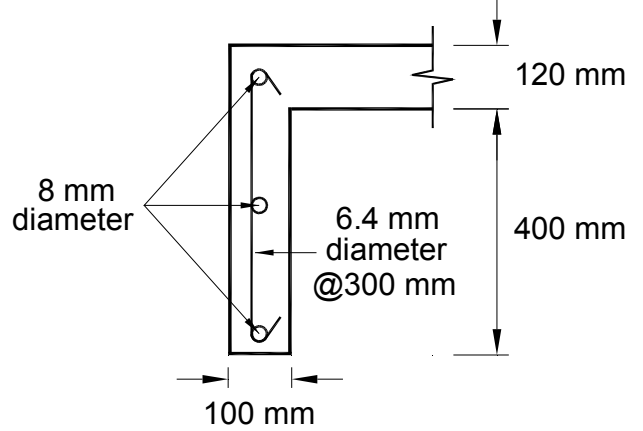

(a) Actual beam

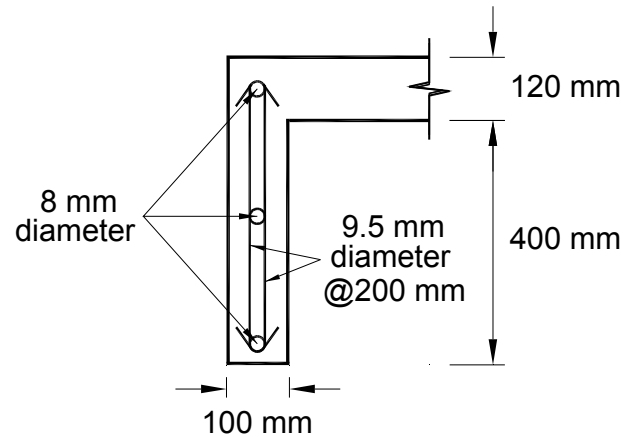

(b) Strengthened beam

Fig. 14. Cross section of the coupling beams

Fig. 14(a) shows a typical existing coupling beam; the transversal reinforcement consists merely of $6.4 \mathrm{~mm}(1 / 4$ in.) single leg spaced at $30 \mathrm{~cm}$. Fig. 14(b) shows a beam with additional transversal reinforcement consisting of $9.5 \mathrm{~mm}(3 / 8 \mathrm{in}$.) closed stirrups spaced at $20 \mathrm{~cm}$.

Push-over analyses of the representative buildings (Table 1) equipped with the strengthened beams are carried out. The structural model has been modified to include flexural hinges at the end sections of the coupling beams; they had not been considered in the models of the existing buildings described in subsection 2.3 because this failure mode was not critical. The hysteretic parameters of such hinges are determined with the help of the RESPONSE-2000 program [49]. The thresholds corresponding to the Damage Limit States are defined in terms of the plastic rotations. For positive bending the values are $0.018 \mathrm{rad}$ (IO), $0.029 \mathrm{rad}$ (LS) and $0.045 \mathrm{rad}(\mathrm{CP})$; for negative bending the values are $0.005 \mathrm{rad}$ (IO), $0.010 \mathrm{rad}$ (LS) and $0.020 \mathrm{rad}$ (CP). Such values are established according to [32]. Fig. 15 shows a comparison between the results of the push-over analyses of building $\mathrm{C} 1 \mathrm{with}$ actual and strengthened coupling beams, respectively; the other structural members have not been modified.

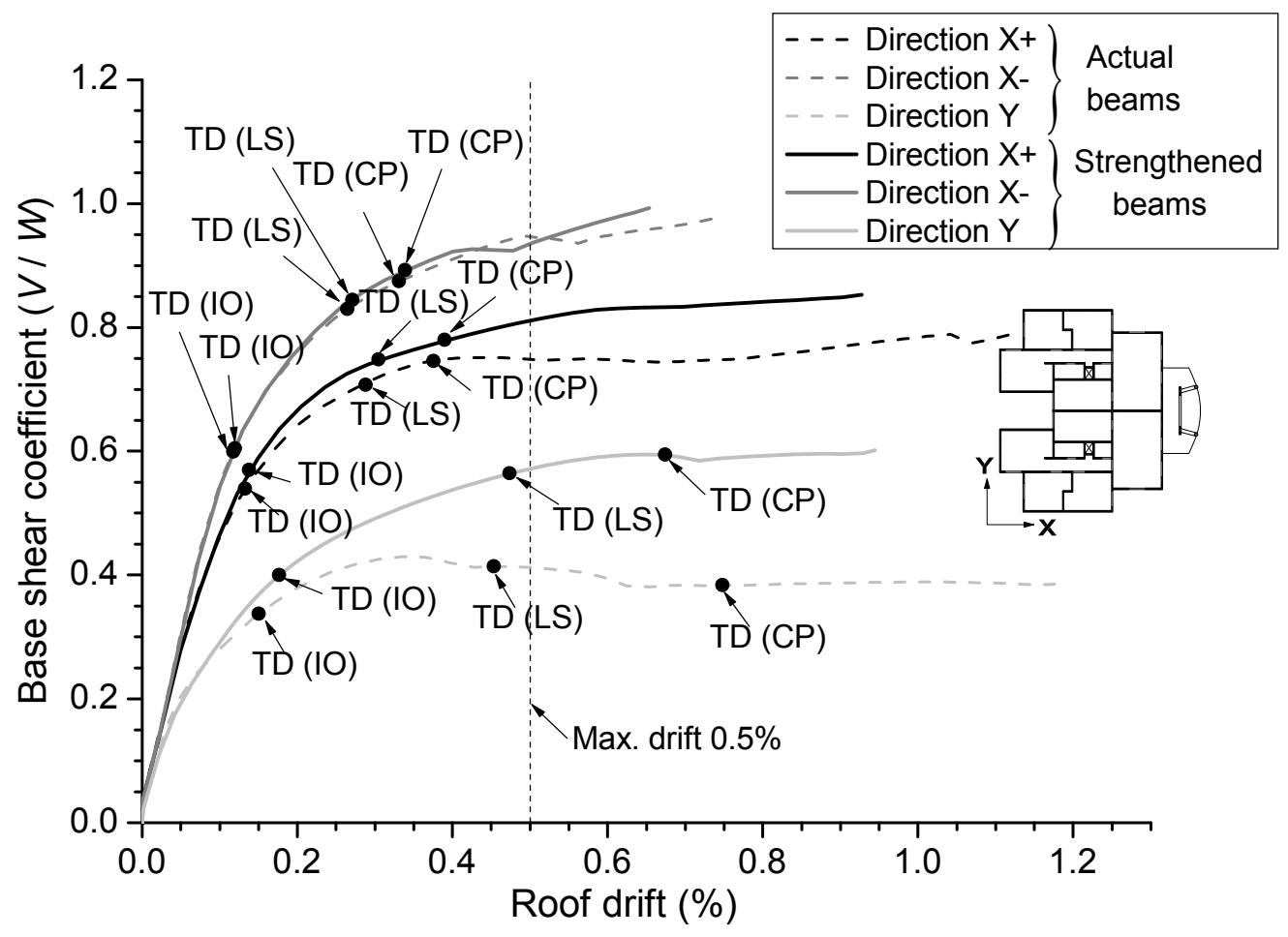

Fig. 15. Capacity curves of building $\mathrm{C} 1$ with actual and strengthened coupling beams

Table 6 shows a comparison of the Damage Limit States and the Target Drifts of building C1 equipped with strengthened coupling beams; for each Damage Limit State, the most critical failure mode is indicated. As in 
Table 3, the cases when the Target Drifts are larger than the corresponding limit states have been highlighted with italics.

Table 6. Main results of the push-over analyses for building C1 with strengthened coupling beams

\begin{tabular}{cccc}
\hline \multirow{2}{*}{ DLS } & $\begin{array}{c}\text { Direction X+ } \\
\text { TD / DLS (\%) }\end{array}$ & $\begin{array}{c}\text { Direction X- } \\
\text { TD / DLS (\%) }\end{array}$ & $\begin{array}{c}\text { Direction Y } \\
\text { TD / DLS (\%) }\end{array}$ \\
\hline IO & $0.138 / 0.192$ (beams, flexural) & $0.117 / 0.172$ (walls, flexural) & $0.176 / 0.092$ (walls, flexural) \\
LS & $0.305 / 0.321$ (walls, flexural) & $0.271 / 0.254$ (walls, flexural) & $0.474 / 0.179$ (walls, flexural) \\
CP & $0.390 / 0.737$ (beams, flexural) & $0.339 / 0.373$ (walls, flexural) & $0.674 / 0.406$ (walls, flexural) \\
\hline
\end{tabular}

Results from Fig. 15 and Table 6 allow deriving the following conclusions for building C1:

- In the directions in which the failure with actual beams arise in the coupling beams (directions $\mathrm{X}+$ and $\mathrm{Y}$, see Table 3), the strengthening of such members has generated a relevant increase in the force capacity of the building.

- The capacity curves with strengthened beams do not exhibit neither flat nor decreasing portions.

- In most of the cases, the strengthening of the beams has generated a slight increase in the Target Drifts. This apparent contradiction might be due to the increase of the spectral ordinates caused by the smaller equivalent damping in the capacity curves corresponding to buildings with strengthened beams.

- The strengthening of the beams has generated a significant increase in the Damage Limit States only in the cases when the most critical failure mode has shifted from "beams" (shear failure) to "beams, flexural" (direction $\mathrm{X}+$ for $\mathrm{IO}$ and $\mathrm{CP}$ ).

- In the cases when the most critical failure mode has shifted from "beams, shear" to "walls, flexure" (direction Y for IO, LS and CP and direction X+ for LS) the strengthening of the beams has generated either a relevant reduction in the Damage Limit States or a negligible modification. This apparent contradiction might be due to the higher bending moment in the base of the walls caused by the effect of the strengthened coupling beams.

- In the cases when the most critical failure mode has not shifted from "walls, flexural" (direction X- for IO, LS and $\mathrm{CP}$ ) the strengthening of the beams has generated a reduction in the Damage Limit States. This effect can be explained as in the previous case.

Similar conclusions can be derived for the other buildings.

\section{Dynamic analyses}

\subsection{Considered inputs}

Three groups of seismic inputs have been considered in the dynamic analyses: accelerograms that are scaled to fit the design response spectrum in the Peruvian code [8], impulsive records, and two Chilean records. The main purpose of the scaled inputs is to provide results comparable with those of the push-over analyses; the other inputs are considered to supply additional relevant information.

The first group is composed of three sets of accelerograms that correspond to the three soil types considered in Table 1, respectively. Each set contains seven pairs [50,51] of EW and NS components. For soft soil, one pair is a historical Peruvian record [52] and the remaining six pairs are synthetic ones having been generated with the SIMQKE program [53]. For intermediate soil, two pairs of accelerograms are historical and five are synthetic. For stiff soil, four pairs are historical and three are synthetic. Each historic accelerogram is scaled to fit the design response spectrum of the Peruvian seismic code [8] according to [50]. The artificial accelerograms have been generated trying to match the design spectrum and accounting for the expected moment magnitude and epicentral distance. Fig. 16 shows the absolute acceleration response spectra of the seven pairs of accelerograms corresponding to intermediate soil conditions; for comparison purposes, the Peruvian design spectrum (termed E.030-SII) is also plotted. For each pair of accelerograms, a single SRSS (square root of the sum of the squares) spectrum is drawn. The recorded accelerograms EQ-SII-Moq and EQ-SII-Pis correspond to the 23-Jun-2001 
Moquegua [54] and to the 15-Aug-2007 Pisco [55,56] earthquakes, respectively; the artificial accelerograms are termed EQ-SII-01 to EQ-SII-05. About the scaling of the historical records, ASCE 7-05 [50] states that each pair of motions should be scaled such that for each period between $0.2 \mathrm{~T}$ and $1.5 \mathrm{~T}$, the average of the SRSS spectra from all horizontal component pairs does not fall below 1.3 times the corresponding ordinate of the design response spectrum by more than $10 \%$; $T$ being the fundamental period of the structure. Since the considered buildings are remarkably stiff (Table 2), only short period ranges are considered in the scaling of the inputs; hence, elsewhere the spectra of the historical records might differ significantly from the design one. Fig. 16 shows that, for the mid and long period ranges, the spectral ordinates of the historical inputs are higher than those of the design spectrum and of the synthetic ones; given the lengthening of the fundamental period due to the nonlinear behavior, these records may be significantly more damaging. Some authors [57-59] have pointed out limitations of the scaling criterion by ASCE 7-05 [50] and have proposed alternative procedures.

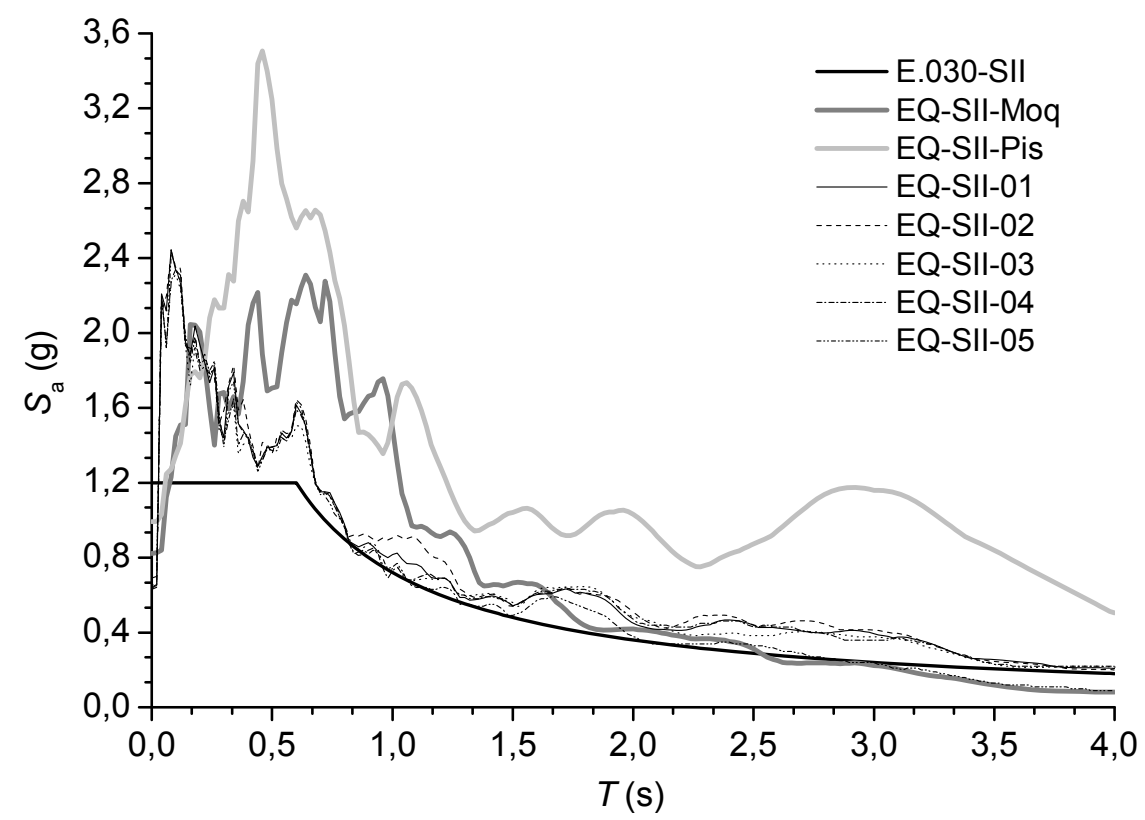

Fig. 16. Response spectra of the scaled accelerograms corresponding to intermediate soil

The second group of inputs consists of six unscaled, two-components, near-fault records: San Fernando 1971 (Pacoima Dam station, termed EQ-SF-PD), Loma Prieta 1989 (Los Gatos station, termed EQ-LP-LG, and Lexington Dam station, termed EQ-LP-LD), Landers 1992 (Lucerne station, termed EQ-LA-LU), Kobe 1995 (JMA station, termed EQ-KO-JMA), and Quindío 1999 (CFLAN station, termed EQ-QU-CF).

The third group of inputs includes two unscaled Chilean records: Viña del Mar 1985 (Llolleo station, termed EQ-VM-LL) and Concepción 2010 (CCSP station, termed EQ-CO-CC). These accelerograms have been introduced because their intensities and subductive mechanisms are similar to those in Peru [54].

\subsection{Results of the dynamic analyses}

Nonlinear dynamic analyses have been carried out on the buildings listed in Table 1 by using the PERFORM-3D program [11,12]. The two components of each input are applied simultaneously; the most damaging components of each input are assumed to shake the buildings in their weak directions. The structural behavior of the buildings is simulated by the model described in subsection 2.3. The damping is represented by a Rayleigh model; as suggested in the references $[60,61]$ the assumed damping ratio is $2.5 \%$.

Fig. 17 displays the maximum inter-storey drifts for directions $\mathrm{X}$ and $\mathrm{Y}$ of building $\mathrm{L} 1$ for the first group of (scaled) inputs; the drift limit equal to $0.5 \%$ [16] is also plotted for comparison purposes. Since the damage thresholds and the Target Drifts for directions $\mathrm{X}+$ and $\mathrm{X}$ - are rather similar (see Fig. 8 and Table 3), Fig. 17(a) 
shows only the absolute maximum values.

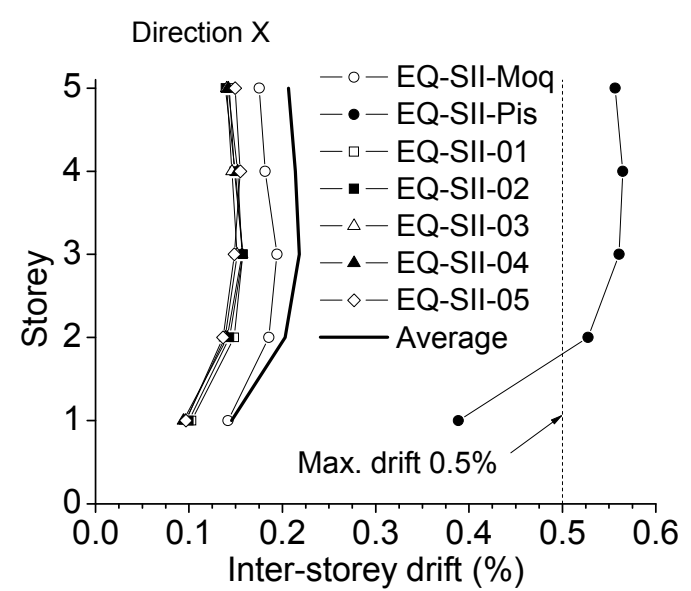

(a) Direction $X$

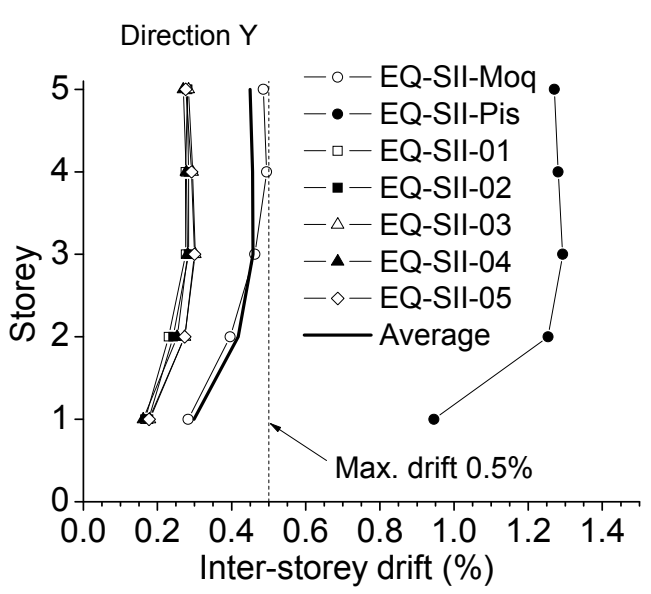

(b) Direction Y

Fig. 17. Maximum inter-storey drifts of building L1 for the scaled inputs ( $1^{\text {st }}$ group)

The results displayed in Fig. 17 show that the artificial inputs (EQ-SII-01 to EQ-SII-05) grossly underestimate the response to the recorded inputs (EQ-SI-Moq and EQ-SI-Pis). As discussed previously, this difference can be explained by their higher spectral amplitudes (Fig. 16) due to the scaling criterion in ASCE 7-05 [50]. This trend is also observed for the other buildings listed in Table 1, though less intensely.

Fig. 18 displays the maximum inter-storey drifts in directions $\mathrm{X}$ and $\mathrm{Y}$ of building $\mathrm{C} 1$ for the second group of inputs; the drift limit equal to $0.5 \%$ [16] is also plotted for comparison purposes. As in Fig. 17, only the absolute maximum values are shown.

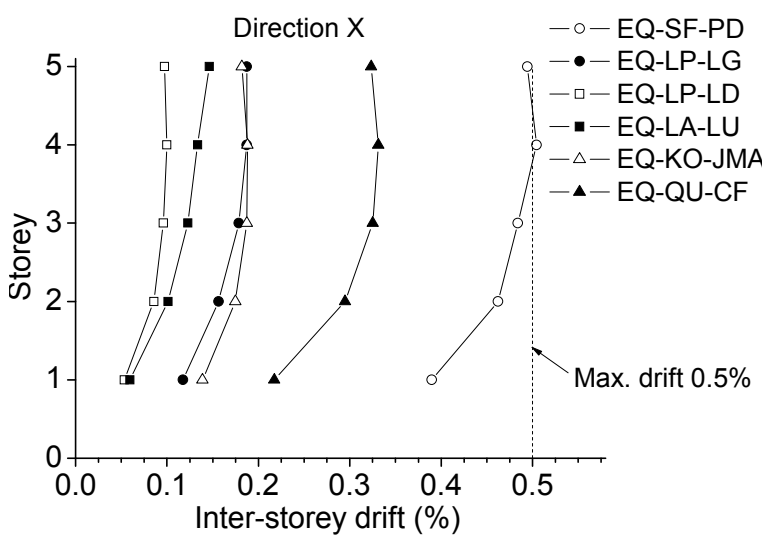

(a) Direction $\mathrm{X}$

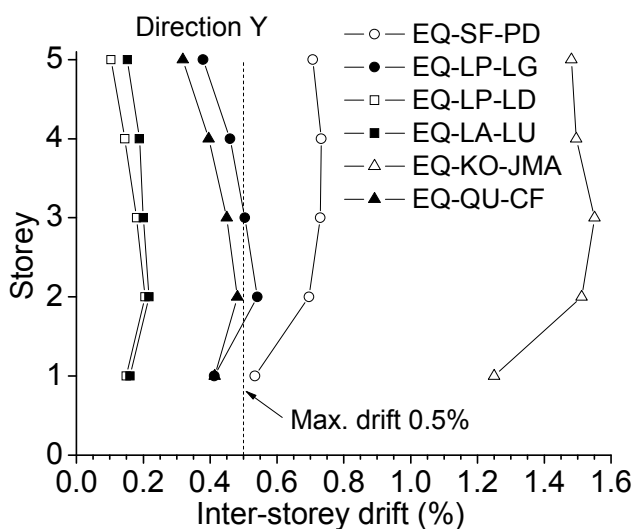

(b) Direction Y

Fig. 18. Maximum inter-storey drifts of building $\mathrm{C} 1$ for the near-source inputs ( $2^{\text {nd }}$ group)

The results from Fig. 18 show that building $\mathrm{C} 1$ is severely damaged in the weak direction; this fact is expectable because for most of the inputs the observed drifts exceed the Damage Limit States [32,33] corresponding to Life Safety (LS) (see Fig. 6). As well, in the weak direction the two most damaging inputs provide drifts over $0.5 \%$. These preliminary results highlight the high damage potential of the considered impulsive inputs.

Fig. 19 displays the maximum inter-storey drifts in directions $\mathrm{X}$ and $\mathrm{Y}$ of building $\mathrm{C} 1$ for the third group of inputs. As in Figs. 17 and 18, only the absolute maximum values are shown. 


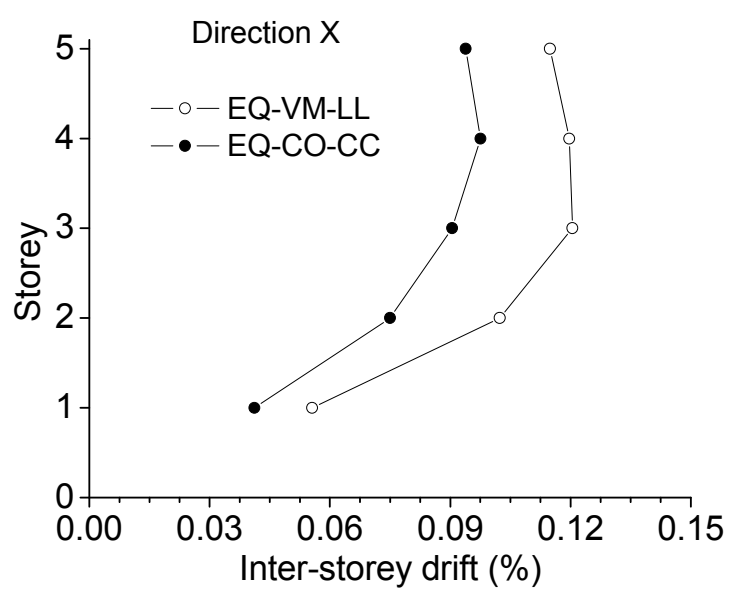

(a) Direction $\mathrm{X}$

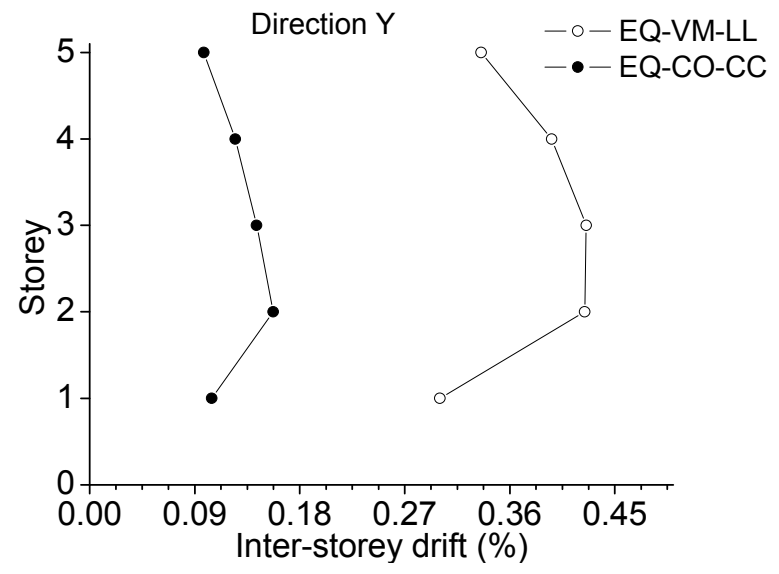

(b) Direction Y

Fig. 19. Maximum inter-storey drifts of building $\mathrm{C} 1$ for the Chilean inputs $\left(3^{\text {rd }}\right.$ group)

Comparison with Fig. 18 shows that these inputs are significantly less demanding. Moreover, the results from Fig. 19 allow deriving the following conclusions:

- In the weak direction the Viña del Mar earthquake generates severe damage in the coupling beams, since the shear demand exceeds the Damage Limit States corresponding to Life Safety (LS) (see Fig. 6).

- The tension strain corresponding to the Viña del Mar earthquake is more than twice the maximum value specified $(1 \%)[29,42]$. It may generate a significant hinging in the base of the walls.

\section{Comparison between push-over and dynamic results}

This section presents a comparison between the results of the static push-over and dynamic analyses for the scaled inputs (first group). Table 7 displays the Target Drifts (corresponding to "Life Safety") obtained from both analyses.

Table 7. Comparison between the LS Target Drifts (\%) from static and dynamic analyses

\begin{tabular}{ccccc}
\hline Building & $\begin{array}{c}\text { Direction X+ } \\
\text { Static / dynamic }\end{array}$ & $\begin{array}{c}\text { Direction X- } \\
\text { Static / dynamic }\end{array}$ & $\begin{array}{c}\text { Direction Y+ } \\
\text { Static / dynamic }\end{array}$ & $\begin{array}{c}\text { Direction Y- } \\
\text { Static / dynamic }\end{array}$ \\
\hline C1 & $0.288 / 0.165$ & $0.264 / 0.137$ & $0.453 / 0.246$ & $0.453 / 0.260$ \\
C2 & $0.442 / 0.219$ & $0.414 / 0.184$ & $0.348 / 0.244$ & $0.348 / 0.197$ \\
L1 & $0.173 / 0.194$ & $0.160 / 0.155$ & $0.324 / 0.406$ & $0.324 / 0.366$ \\
L2 & $0.072 / 0.069$ & $0.092 / 0.064$ & $0.342 / 0.251$ & $0.342 / 0.234$ \\
L3 & $0.083 / 0.050$ & $0.069 / 0.045$ & $0.522 / 0.298$ & $0.522 / 0.284$ \\
L4 & $0.136 / 0.078$ & $0.127 / 0.083$ & $0.176 / 0.120$ & $0.180 / 0.122$ \\
L5 & $0.207 / 0.157$ & $0.180 / 0.154$ & $0.177 / 0.138$ & $0.181 / 0.131$ \\
\hline
\end{tabular}

Results from Table 7 show that, apart from building L1, the drifts obtained from the push-over analyses are larger than those arising from the dynamic analyses; the ratios range from 2.25 (building $\mathrm{C}_{2}$, direction $\mathrm{X}_{-}$) to 1.04 (building L2, direction $\mathrm{X}+$ ). These differences can be explained by the simplified conservative assumptions in the push-over analyses; being particularly relevant for wall buildings [62]. The exception for building L1 might be due to the extraordinarily high response for the two historical inputs (Fig. 17).

\section{Preliminary design recommendations}

The results of this study allow concluding that the thin shear-wall buildings designed with the previous version of the Peruvian seismic design code [8] may have an inadequate seismic behavior; even, the consideration of the last version of such code [16], might be insufficient. The following preliminary design recommendations are formulated: 
- The wall density in any direction should be, at least, equal to about $4 \%$. As well, the moments of inertia (including the contribution of the flanges), should be, at least, 4\%o of those of the plan area.

- The coupling beams should be designed following usual seismic guidelines. In such a case, even keeping their width equal to the one of the wall, the benefits might be relevant.

- The soil-structure interaction is relevant and should be accounted for.

- The accurate calculation of the natural periods is of little interest because these buildings fall usually into the constant acceleration branch of the design spectrum. Moreover, the early onset of cracking in the walls generates lengthening of such period even for low seismicity regions.

Only economical and feasible design recommendations are formulated since nowadays mass high-quality construction is not affordable by the involved countries, as discussed previously.

\section{Conclusions}

This work presents a numerical seismic assessment of seven existing representative thin shear-wall and mid-height buildings located in Peru. Both static and dynamic nonlinear analyses have been conducted. Apart from the particular interpretations of the results included in the text, the overall conclusions arising from this research are:

- The seismic strengths of all the analyzed buildings are insufficient. For the Immediate Occupancy (IO) performance level, five of the seven considered buildings exhibit inadequate behavior, at least in one direction. For the Life Safety (LS) and Collapse Prevention (CP) levels, the numbers of buildings that behave unacceptably are seven and four, respectively.

- The better performances, in terms of the ratios between the Target Drifts and the corresponding Damage Limit States, correspond to the strong directions (those with highest densities of walls).

- In most of the cases the Damage Limit States for Immediate Occupancy, Life Safety and Collapse Prevention are achieved first in the coupling beams. The next failure mode corresponds to the flexure of the walls.

- Minor and feasible modifications in the coupling beams might provide relevant improvements in the seismic performance of these buildings.

The extension of these conclusions to the majority of thin-wall buildings can be done only with extreme caution, given the preliminary character of this research.

One of the major benefits arising from this research is a deeper knowledge about the seismic behavior of these buildings. This understanding allows identifying further research needs, useful for the next stages.

\section{ACKNOWLEDGEMENTS}

This work has received financial support from the Spanish Government under project CGL2008-00869/BTE. The stay of H. Gonzales in Barcelona has been supported by the Catalan Agency for Management of University and Research Grants (AGAUR), grant \# DEBEQ-10020. The authors are also thankful to Eng. Gabriela Medina for providing experimental information.

\section{REFERENCES}

[1] Mejía L, Ortiz JC, Osorio LI. Concrete shear-wall buildings. World Housing Encyclopedia (http://www.world-housing.net/whereport1 view.php?ID=100107; date of access: October 2010). Earthquake Engineering Research Institute and International Association for Earthquake Engineering, Colombia/Report 109, 2004.

[2] Carrillo J, Alcocer S, Uribe R. Prediction of shear performance of concrete walls for housing. XVII National Congress of Earthquake Engineering, Puebla, Mexico, 2009 (in Spanish).

[3] Muñoz A, Delgado R, Peña C. Seismic performance of limited ductility shear-wall buildings, Catholic University of Peru, Lima, 2006 (in Spanish).

[4] Yáñez D. Linear seismic analysis of tunnel form buildings. Bach. Thesis, Faculty of Civil Engineering, Los Andes University, Mérida, Venezuela, 2006 (in Spanish)

[5] ICC (International Code Council). International Building Code (IBC-2006). Falls Church, Virginia, 2006.

[6] CEN - EN 1998-1. Eurocode 8 (EC-8). Design of structures for earthquake resistance, European Committee for Standardization (CEN), Bruxelles, Belgium, 2005. 
[7] NSR-10, Colombian Code for Earthquake-Resistant Construction, Ministerio de Ambiente, Vivienda y Desarrollo Territorial, 2010 (in Spanish).

[8] E.030, Building Technical Code. Earthquake-resistant design. Ministry of housing, construction and sewage, Lima, Peru, 2003 (in Spanish).

[9] FONDONORMA (Fondo para la Normalización y Certificación de la Calidad). Venezuelan Code. Design and construction with structural concrete, 1753:2006 ( $1^{\text {st }}$ version), 2006 (in Spanish).

[10] NTCS-2004, Additional technical standards for earthquake resistant design. Construction Regulations for the Federal District, Gaceta Oficial del Departamento del Distrito Federal, 2004 (in Spanish)

[11] CSI. PERFORM-3D. Nonlinear Analysis and Performance Assessment for 3D Structures, V.4.0.3. Computers and Structures, Inc. Berkeley, CA, 2007.

[12] Powell G. Modeling for structural analysis. Computers and Structures, Inc. Berkeley, CA, Ed., 2010.

[13] San Bartolomé A, Rojas LA, Koo JI. Experimental study of two criteria from ACI used to confine edges of reinforced concrete walls, Catholic University of Peru, Lima, 2007 (in Spanish).

[14] ACI Committee 318. Building code requirements for structural concrete (ACI 318-08) and commentary. American Concrete Institute (ACI), Farmington Hills, Mich, 2008.

[15] UBC. Uniform Building Code. International Conference of Building Officials, Whittier, California, 1997.

[16] EMDL, Design standards for buildings with limited ductility concrete walls. Association of Engineers of Peru, Lima, 2004 (in Spanish).

[17] Wallace JW, Orakcal K. ACI-318-99 Provisions for Seismic Design of Structural Walls. ACI Structural Journal 2002; 99(4):499-508.

[18] Zavala C, Gálvez V. Study of the lateral behavior of AGV walls. Research report. CISMID/FIC/UNI, Lima, Peru, 1998 (in Spanish).

[19] San Bartolomé A, Muñoz A, Villagarcía M, Acuña C. Seismic behavior of concrete walls reinforced with welded wire mesh, Catholic University of Peru, Lima, 2003 (in Spanish).

[20] Medina G. Full-scale experimental study of the behavior of concrete walls and one assembly reinforced with welded wire mesh. Bach. Thesis, Department of Civil Engineering, National University of Engineering, Lima, Peru, 2005 (in Spanish).

[21] Tremblay R, Léger P, Tu J. Inelastic seismic response of concrete shear-walls considering P-delta effects. Canadian Journal of Civil Engineering $2001 ; 28(4): 640-655$.

[22] Fenwick RC, Davidson BJ, Chung BT. P-delta actions in seismic resistant structures. Bulletin of the New Zealand Society for Earthquake Engineering 1992; 25(1):56-69.

[23] NBCC. National Building Code of Canada. Institute for Research in Construction, National Research Council of Canada, Ottawa, Ont., 2005.

[24] NZS 3101. Concrete structures standard part 1 and 2. Private bag 2439. Wellington 6020, New Zealand, 1995.

[25] NCh 430.EOf61. Reinforced Concrete - Part II, National Institute of Standardization, Chile, 1999 (in Spanish).

[26] Paulay T, Priestley MJN. Seismic design of reinforced concrete and masonry buildings. John Wiley, 1992.

[27] Hognestad E, Hanson NW, McHenry D. Concrete stress distribution in ultimate strength design. ACI Journal, Proceedings 1955; 52(4):455-479.

[28] Saatcioglu M, Razvi S. Strength and Ductility of Confined Concrete. Journal of Structural Engineering (ASCE) 1992; 118(6):1590-1607.

[29] Powell G. Detailed example of a tall shear-wall building, Computers and Structures, Inc., (CSI). Berkeley, CA, 2007.

[30] Gálvez V, Burgos M, Ortiz A. Proposal of a response reduction factor for concrete walls reinforced with conventional bars and welded wire mesh, Lima, Peru, 2008 (in Spanish).

[31] Gérin M, Adebar P. Accounting for shear in seismic analysis of concrete structure. 13th World Conference on Earthquake Engineering, Vancouver, 2004, CD Rom Paper No. 939, 15 pp.

[32] FEMA-356. Prestandard and commentary for the seismic rehabilitation of buildings, Federal Emergency Management Agency (FEMA 356), Washington, D.C, 2000

[33] ASCE 41-06. Seismic rehabilitation of existing buildings. ASCE/SEI 41-06, American Society of Civil Engineers, Reston, VA, 2007.

[34] ASCE. Seismic rehabilitation of existing buildings (ASCE/SEI 41-06, Including Supplement \# 1), American Society of Civil Engineers, Reston, VA, 2007.

[35] PERFORM Components and Elements, Computers and Structures, Inc., (CSI). Berkeley, CA, 2006.

[36] PERFORM-3D, Nonlinear Analysis and Performance Assessment for 3D Structures, V.4, User Guide, Computers and Structures, Inc., (CSI). Berkeley, CA, 2006.

[37] Chopra AK, Goel RK. A Modal Pushover Analysis Procedure to Estimate Seismic Demands for Buildings: Theory and Preliminary Evaluation. PEER Report 2001/03, Pacific Earthquake Engineering Research Center, 2001.

[38] CEN - EN 1992-1. Eurocode 2 (EC-2). Design of concrete structures, European Committee for Standardization (CEN), Bruxelles, Belgium, 2002.

[39] SEAOC. Vision 2000 a framework for Performance-Based Engineering, Structural Engineers Association of California, California, 1995.

[40] Panneton M, Léger P, Tremblay R. Inelastic analysis of a reinforced concrete shear-wall building according to the National Building Code of Canada 2005. Canadian Journal of Civil Engineering 2006; 33(7):854-871.

[41] Heiderbrecht A. (2003). Overview of seismic provisions of the proposed 2005 edition of the National Building Code of Canada. Canadian Journal of Civil Engineering 2003; 30(2):241-254.

[42] Panagiotou M, Restrepo JI. Lessons Learnt from the UCSD Full-scale Shake Table Testing on a 7-Story Residential Building Slice, SEAOC convention, Lake Tahoe, September 26-29, 2007.

[43] Filiatrault A, Anderson DL, DeVall RH. Effect of weak foundation on the seismic response of core wall type buildings. Canadian Journal of Civil Engineering 1992; 19(3):530-539.

[44] Chaallal O. Seismic response of flexibly supported coupled shear-walls. Journal of Structural Engineering, ASCE 1996; 122(10):1187-1197.

[45] Anderson DL. Effect of foundation rocking on the seismic response of shear-walls. Canadian Journal of Civil Engineering 2003; 30(2):360-365.

[46] Murphy MA, Lew M, The importance of performance-based geotechnical parameters for nonlinear analysis. ATC \& SEI 2009 Conference on Improving the Seismic Performance of Existing Buildings and Other Structures, San Francisco, 2009.

[47] Reynolds A, Chiewanichakorn M. Benefits of Using Nonlinear Analysis on Seismic Retrofit from Structural Engineering Standpoint. ATC \& SEI 2009 Conference on Improving the Seismic Performance of Existing Buildings and Other Structures, San Francisco, 2009.

[48] Orakdöen E, Girgin K, Boduroglu MH, Büyükl B, Gökçe T. Performance Evaluation of a Strengthened Building Considering the Soil-Structure Interaction, Journal of Earthquake Engineering 2008; 12(1):222-233.

[49] Bentz E, Collins MP. RESPONSE2000, V.1.0.5. Toronto University, Department of Civil Engineering, Toronto, Ontario, Canada, 2000.

[50] ASCE 7-05. Minimum design loads for buildings and other structures. ASCE/SEI 7-05, American Society of Civil Engineers, Reston, VA, 2005.

[51] Wallace JW. Performance-Based Design of Tall Reinforced Concrete Core Wall Buildings. Earthquake Engineering in Europe. Geotechnical, Geological, and Earthquake Engineering 2010, 279-307. Springer. 
[52] CISMID: Peruvian-Japanese Center for Earthquake Engineering Research and Disaster Mitigation, Faculty of Civil Engineering, National University of Engineering, Lima, http://www.cismid-uni.org/redacis/index.php [6 October 2010].

[53] Gasparini DA, Venmarcke EH. SIMQKE: A Program for Artificial Motion Generation, Department of Civil Engineering, MIT, Cambridge, Massachusetts, USA, 1976.

[54] Pritchard M, Norabuena O, Li C, Boroschek R, Comte D, Simons M, Dixon T, Rosen P. Geodetic, teleseismic, and strong motion constraints on slip from recent southern Peru subduction zone earthquakes. Journal of Geophysical Research 2007; Vol. 112: 0148-0227.

[55] EERI. Learning from Earthquakes - The Pisco, Peru, earthquake of August 15, 2007. Earthquake Engineering Research Institute, Special Earthquake Report, 2007.

[56] Tavera H, Bernal I, Stresser F, Arango-Gaviria M, Alarcon J, Bommer J. Ground Motions Observed During The 15 August 2007 Pisco, Peru, Earthquake, Bulletin of Earthquake Engineering 2008; 7(1):71-111.

[57] Sumer A, Kersting RA, Hutchinson DA. Nonlinear Analysis of Pre-Northridge Steel High-Rise Building using Modal-Pushover-Based Ground Motion Scaling Procedure, Proc. of the ATC/SEI - Conference on Improving the Seismic Performance of Existing Buildings and Other Structures, Dec. 9-11, 2009.

[58] Kalkan E, Çelebi M. Assessment of ASCE-7 Ground Motion Scaling Method Using Computer Model of Instrumented High-Rise Building. ATC \& SEI 2009 Conference on Improving the Seismic Performance of Existing Buildings and Other Structures, San Francisco, 2009.

[59] Kalkan E, Chopra AK. Modal-Pushover-based Ground Motion Scaling Procedure, Journal of Structural Engineering (ASCE), Special Issue 2010; in press.

[60] Wallace JW, Moehle JP. Evaluation of ATC requirements for soil-Structure interaction using data from the 3 March 1985 Chile earthquake, Earthquake Spectra 1990; 6(3):593-611.

[61] Boroschek R, Yáñez FV. Experimental verification of basic analytical assumptions used in the analysis of structural wall buildings. Engineering Structures 2000; 22(6): 657-669.

[62] Kazaz I, Yakut A, Gülkan P. Seismic response assessment of a stiff structure. Earthquake engineering and structural dynamics 2006; 35(6):737-759. 